\title{
A novel plant-fungal association reveals fundamental sRNA and gene expression reprogramming at the onset of symbiosis
}

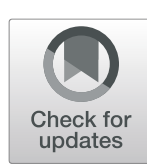

Ena Šečić ${ }^{1}$ Silvia Zanini ${ }^{1}$ Daniel Wibberg ${ }^{2}$, Lukas Jelonek ${ }^{3}$, Tobias Busche ${ }^{2}$, Jörn Kalinowski ${ }^{2}$, Sabrine Nasfi ${ }^{1}$, Jennifer Thielmann ${ }^{1}$, Jafargholi Imani ${ }^{1}$, Jens Steinbrenner ${ }^{1}$ and Karl-Heinz Kogel ${ }^{1 *}$ (D)

\begin{abstract}
Background: Beneficial associations between plants and microbes are widespread in nature and have been studied extensively in the microbial-dominant environment of the rhizosphere. Such associations are highly advantageous for the organisms involved, benefiting soil microbes by providing them access to plant metabolites, while plant growth and development are enhanced through the promotion of nutrient uptake and/or protection against (a)biotic stresses. While the establishment and maintenance of mutualistic associations have been shown to require genetic and epigenetic reprogramming, as well as an exchange of effector molecules between microbes and plants, whether short RNAs are able to effect such changes is currently unknown. Here, we established an interaction between the model grass species Brachypodium distachyon (Bd, Pooideae) and the beneficial fungal root endophyte Serendipita indica (Si, syn. Piriformospora indica, Sebacinales) to elucidate RNA interference-based regulatory changes in gene expression and small (s)RNA profiles that occurred during establishment of a Sebacinalean symbiosis.

Results: Colonization of $B d$ roots with $S i$ resulted in higher grain yield, confirming the mutualistic character of this interaction. Resequencing of the Si genome using the Oxford Nanopore technique, followed by de novo assembly yielded in 57 contigs and 9441 predicted genes, including putative members of several families involved in sRNA production. Transcriptome analysis at an early stage of the mutualistic interaction identified 2963 differentially expressed genes (DEG) in Si and 317 in Bd line 21-3. The fungal DEGs were largely associated with carbohydrate metabolism, cell wall degradation, and nutrient uptake, while plant DEGs indicated modulation of (a)biotic stress responses and defense pathways. Additionally, 10\% of the upregulated fungal DEGs encode candidate protein effectors, including six DELD proteins typical for Sebacinales. Analysis of the global changes in the sRNA profiles of both associated organisms revealed several putative endogenous plant sRNAs expressed during colonization belonging to known micro (mi)RNA families involved in growth and developmental regulation. Among Bd- and Sigenerated sRNAs with putative functions in the interacting organism, we identified transcripts for proteins involved in circadian clock and flowering regulation as well as immunity as potential targets of fungal sRNAs, reflecting the beneficial activity of Si.
\end{abstract}

\footnotetext{
* Correspondence: Karl-Heinz.Kogel@agrar.uni-giessen.de

${ }^{1}$ Institute of Phytopathology, Centre for BioSystems, Land Use and Nutrition, Justus Liebig University, 35392 Giessen, Germany

Full list of author information is available at the end of the article
}

\section{$\triangle B M C$}

(c) The Author(s). 2021 Open Access This article is licensed under a Creative Commons Attribution 4.0 International License, which permits use, sharing, adaptation, distribution and reproduction in any medium or format, as long as you give appropriate credit to the original author(s) and the source, provide a link to the Creative Commons licence, and indicate if changes were made. The images or other third party material in this article are included in the article's Creative Commons licence, unless indicated otherwise in a credit line to the material. If material is not included in the article's Creative Commons licence and your intended use is not permitted by statutory regulation or exceeds the permitted use, you will need to obtain permission directly from the copyright holder. To view a copy of this licence, visit http://creativecommons.org/licenses/by/4.0/ The Creative Commons Public Domain Dedication waiver (http://creativecommons.org/publicdomain/zero/1.0/) applies to the data made available in this article, unless otherwise stated in a credit line to the data. 
Conclusions: We detected beneficial effects of Si colonization on Bd growth and development, and established a novel plant-mutualist interaction model between these organisms. Together, the changes in gene expression and identification of interaction-induced sRNAs in both organisms support sRNA-based regulation of defense responses and plant development in $B d$, as well as nutrient acquisition and cell growth in Si. Our data suggests that a Sebacinalean symbiosis involves reciprocal sRNA targeting of genes during the interaction.

Keywords: Brachypodium distachyon, Genome sequencing, Sebacinalean symbiosis, Serendipita indica, Small RNAs

\section{Background}

Mutualistic associations between beneficial microbes and plants are widespread and highly advantageous, especially in the microbial-dominant environment of the rhizosphere. This relationship benefits soil microbes by providing them access to plant metabolites; in return, they enhance plant growth and development by promoting nutrient uptake and/or protection against (a)biotic stresses $[1,2]$. The beneficial or parasitic outcome of a plant-microbe interaction is governed by the genotype and physiological status of the host, identity of the microbe, and environmental factors such as soil type and nutrient availability $[3,4]$. The establishment and maintenance of mutualistic associations (here called symbiosis) require genetic and epigenetic reprogramming and metabolome modulation by the exchange of effector molecules between the beneficial microbe and the plant $[5,6]$. Beneficial microbes have a significant impact on crop production, due to their effects on plant health and yield. However, considerable gaps in knowledge prior to their establishment in agricultural practice remain, including systemic identification of microbial abundance and diversity in various ecosystems, understanding the influence of climate, soil conditions, management practices, and, lastly, elucidating the intricacies of molecular mechanisms governing establishment of colonization and nutrient acquisition [7].

Crucial for regulation of gene expression, RNA interference (RNAi) is a well-known eukaryotic gene silencing mechanism [8], mediated by small RNAs (sRNAs) of 20-24 nucleotides (nt) in size and RNAi-associated proteins, primarily from the Argonaute (AGO), Dicerlike (DCL) and RNA-dependent RNA polymerase (RdRP) families [9]. DCLs generate sRNAs from longer RNA molecules, whereas AGOs bind sRNAs within an RNA-induced silencing complex (RISC). In the context of plant-microbe interactions, microbial protein effectors are known to promote pathogen colonization by suppressing host immune responses [10] and have been described in mutualistic associations as well [5], including the Sebacinalean symbiosis [11]. Recent findings suggest that sRNAs, through RNAi-based regulatory mechanisms, also can serve as effectors of pathogenic microbes [12], whereby the sRNA is secreted to suppress translation of a host mRNA via RNAi. Conversely, plants can secrete sRNAs that target virulence-associated mRNAs in the microbe [13]. This transfer of sRNAs and subsequent gene silencing in the target organism is called cross-kingdom RNAi [12].

We studied the association of the beneficial fungus Serendipita indica ( $\mathrm{Si}$ ) with the model grass Brachypodium distachyon ( $B d$, purple false brome, Pooideae [14];). $\mathrm{Si}$ is an endophytic fungus belonging to the order Sebacinales that colonizes the rhizodermis and cortex of a large spectrum of plants [15]. Si serves as an excellent model for beneficial microbes as it (i) primes plants for disease resistance against biotrophic [16] and necrotrophic [17] fungi, oomycetes [18], and viruses [19]; (ii) enhances the tolerance of plants against abiotic stress [20]; (iii) promotes growth and yield [21]; (iv) has a sequenced $25 \mathrm{Mb}$ genome [22]; and (v) is genetically transformable and culturable in axenic conditions [23]. Si initially undergoes a biotrophic growth phase during Arabidopsis (Arabidopsis thaliana) and barley (Hordeum vulgare) colonization, with suppression of innate immune responses [24, 25] and activation of induced systemic resistance [16]. Subsequently, $\mathrm{Si}$ colonization of barley enters a cell-death associated phase and switches to a saprophytic lifestyle [26, 27].

$B d$ is a temperate grass species belonging to the Pooideae subfamily and a model for genetic studies of stress resistance and yield parameters of cereals [28]. $B d$ is self-pollinating, genetically transformable, easy to cultivate, and has a sequenced genome of $272 \mathrm{Mb}$ [29-31]. It shares evolutionary proximity and broad synteny with complex crop genomes, such as wheat and rice [14], and is a host for major cereal pathogens [32]. Additionally, RNAi is operational in $B d$, with proven alteration of micro RNA (miRNA) expression patterns in response to abiotic stresses [33, 34]. In silico analyses revealed that the $B d$ genome, similar to other cereals, contains an expansion of DCL and AGO families [35].

Currently, the significance of cross-kingdom RNAi in mutualistic interactions is largely unknown. A recent in silico study predicted that the arbuscular mycorrhizal fungus Rhizophagus irregularis generates sRNAs, which have predicted targets in the host plant Medicago truncatula [36]. Moreover, tRNA-derived sRNA fragments from rhizobial bacteria were shown to regulate host nodulation-associated genes by utilizing the host's RNAi machinery [37]. To investigate the role of sRNAs in 
another agronomically relevant mutualistic interaction, we established a protocol for $\mathrm{Si}$ colonization of the model Pooideae $B d$. Additionally, integrative highthroughput sequencing and transcriptome analysis assessed symbiosis-associated changes in the mRNA and sRNA expression patterns of both organisms. We discuss here possible sRNA-based regulation that might be critical for the establishment of the Sebacinalean symbiosis.

\section{Results}

\section{Brachypodium distachyon Bd21-3 forms a mutualistic interaction with Serendipita indica}

To investigate whether $B d$ can develop a beneficial interaction with $S i$, we established an inoculation protocol using one-week-old seedlings of $B d$ line $\mathrm{Bd} 21-3$, with dip-inoculation in $5 \times 10^{5}$ chlamydospores $\mathrm{ml}^{-1}$ for $3 \mathrm{~h}$. Comparison of grain production in fully mature, colonized vs. non-colonized plants grown in soil showed that $\mathrm{Si}$ increased the number of filled grains/plant by $49.9 \%$ (Fig. 1a, Additional file 1), and total grain weight/plant increased by $38.1 \%$ (Fig. 1b, Additional file 1). Consistent with the observation that Si-colonized Bd21-3 plants flower several days earlier than control plants, they exhibited a $32.2 \%$ increase in the number of spikelets at 2 months after inoculation (Fig. 1c, Additional file 1). Concordantly, growth and biomass analyses of Bd21-3 seedlings revealed a significant $8.6 \%$ increase in shoot length (Fig. 1d) upon $S i$ colonization.

Further analysis of Bd21-3 seedlings indicated that $S i$ colonization increased lateral root growth, as early as 4 days post inoculation (4 DPI, Additional file 2: Figure S1a). By 25 DPI, roots showed a more extensively branched structure (Additional file 2: Figure S1b). Microscopy of Si-inoculated Bd21-3 roots confirmed root surface colonization and proliferation of fungal spores after staining with chitin-specific WGA-AF 488 at 4 DPI (Fig. 2a-d) and further on at 7 DPI and 14 DPI (Additional file 2: Figure S2). Inter- and intracellular colonization of $\mathrm{Bd} 21-3$ cells in the root differentiation zone also was visible after WGA-AF 488 and propidium iodide staining (Fig. 2e-h). These results suggest that establishment of a mutualistic symbiosis correlates with observable phenotypic changes by $4 \mathrm{DPI}$; thus, this time point was used to further investigate the $\mathrm{Bd} 21-3-\mathrm{Si}$ system.

\section{Resequencing of the Si genome}

To improve $S i$ assembly, the genome was resequenced using MinION (25,167 reads, $324 \mathrm{Mb})$ and MiSeq $(18,225,814$ reads, $5.46 \mathrm{~Gb})$; together they yielded approx. $6.0 \mathrm{~Gb}$ of sequence information. De novo assembly of the Nanopore sequence reads generated 57 contigs, accounting for a total length of $24.7 \mathrm{Mb}$ and a N50 of $1.3 \mathrm{Mb}$. The draft genome sequence features GC content of $50.8 \%$, similar to the first genome version with 2,359 contigs and GC content of 50.7\% [22]. Analyses using the eukaryotic gene prediction tool Genemark-ES 4.33 [38] revealed 9441 predicted genes ( $75 \%$ of the genome; 59,045 exons), 9498 intergenic regions (25\% of the genome), and a gene density of 380.68 genes/Mbp (Additional file 2: Table S1). Annotation of the Si genes using a GenDB version designed to process eukaryotic genomes possessing multi-exon genes $[39,40]$ revealed that 4756 have a predicted function. Comparison of predicted genes from the resequenced $\mathrm{Si}$ genome (Si-2020) vs. the 2011 assembly [22] indicated that the vast majority are shared (90.3\%), with 915 genes unique to the Si2020 genome (Additional file 2: Figure S3). There is a reduction in gene model numbers relative to the 2011 assembly, which can be attributed to improved gene prediction tools for eukaryotic organisms and a considerably reduced number of contigs. Additionally, Si shares 2585 genes with another member of the Sebacinales, Serendipita vermifera, while 156 genes are shared only with the ectomycorrhizal fungus Laccaria bicolor and 2729 genes are common in all three species (Additional file 2: Figure S4).

\section{Establishment of the Si-Bd symbiosis is associated with extensive transcriptional reprogramming}

To assess how the symbiotic interaction affects gene expression in both organisms, mRNA was sequenced and analyzed (Additional file 2: Table S2) from the roots of $\mathrm{Si}$-colonized Bd21-3 seedlings (sample $\mathrm{Bd}-\mathrm{Si}$ ) and mocktreated plants $(\mathrm{Bd}-\mathrm{C})$ at $4 \mathrm{DPI}$, and from 4-week-old axenic $\mathrm{Si}$ cultures (Si-ax). Comparison of reads between Bd-Si and Si-ax identified 2963 differentially expressed fungal genes (DEGs, DESeq2: Wald test, BenjaminiHochberg (BH) adjustment, padj <0.05), which accounts for $31.4 \%$ of the 9441 predicted Si genes. Comparison of reads from $\mathrm{Bd}-\mathrm{Si}$ and $\mathrm{Bd}-\mathrm{C}$ revealed 317 plant DEGs (0.66\% out of approximately 47,917 protein-coding transcripts disclosed in the JGI v1.1 annotation, padj $<0.05$ ). The interaction-responsive DEGs in Si and Bd21-3, split into up- and downregulated groups are shown in Fig. 3.

All significant DEGs were submitted to gene ontology term analysis against the reference background for $B d$ and a customized $\mathrm{Si}$-specific background. The resulting enriched terms relate to metabolic, mainly redox processes and catalytic activity functions (Additional file 2: Table S3). Of the 25 highly downregulated Si DEGs, many encode proteins associated with metabolic reprogramming networks involved in nutrient exchange and adaptation to nutrient availability (Table 1). By contrast, highly upregulated $\mathrm{Si}$ DEGs encode for proteins involved in fungal catalytic and hydrolytic processes. This suggests that by 4 DPI, $S i$ has entered a saprophytic-like 


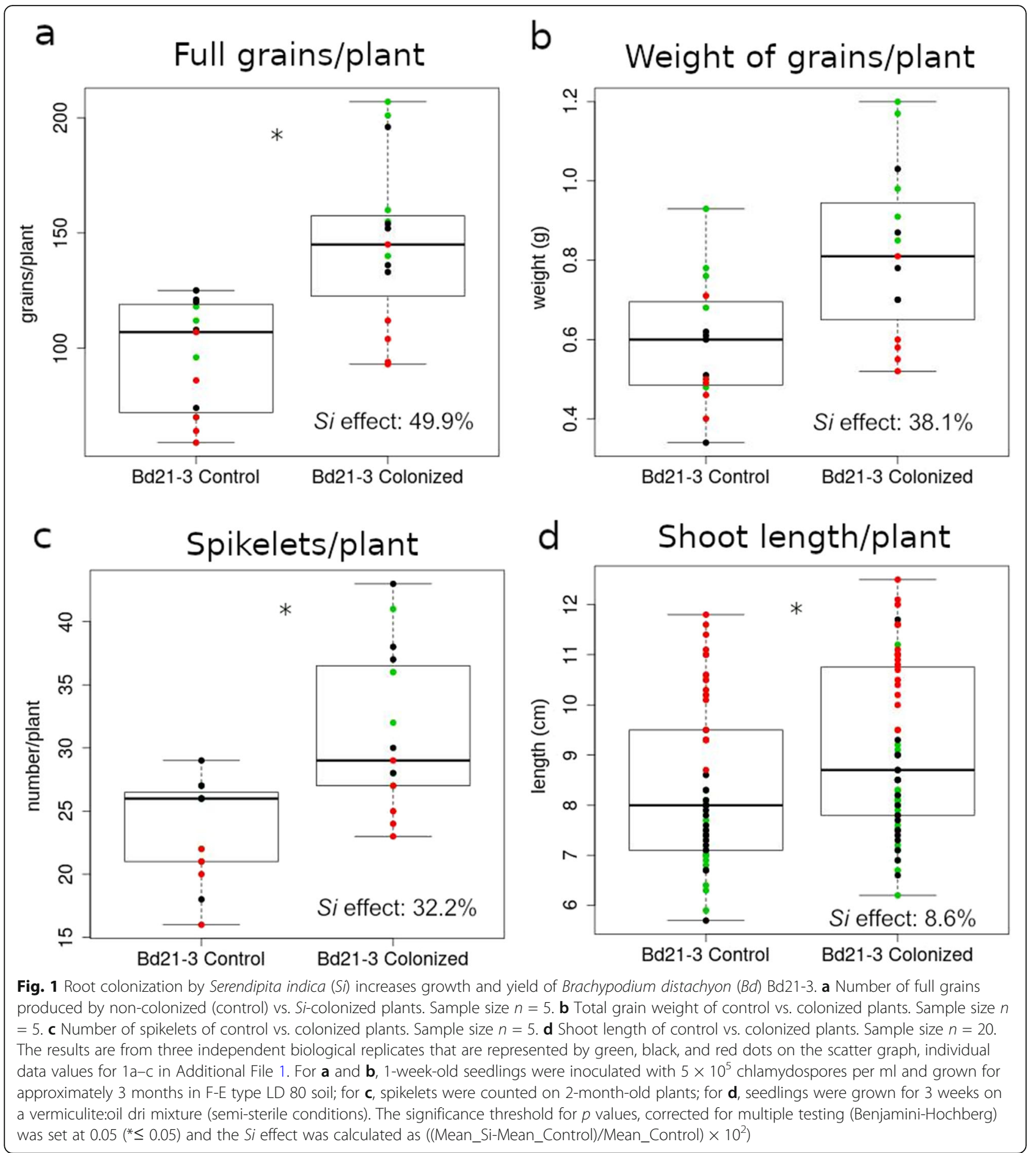

growth phase similar to that detected in barley roots [22]. To investigate whether any Si DEG encodes effector proteins, a computational pipeline [41] was used to mine 982 genes identified in the $\mathrm{Si}-2020$ genome that encode signal peptide-containing proteins, resulting in 480 putative protein effector genes. In total, 174 (36\%) of these were significantly upregulated during colonization of Bd21-3 (Additional file 2: Table S4), including six DELD family proteins [22]. In Bd21-3, many of the highly downregulated interactionresponsive DEGs encode transcription factors or proteins associated with stress responses or circadian clock regulation. Those showing high levels of upregulation include genes linked to immune responses and hormone 

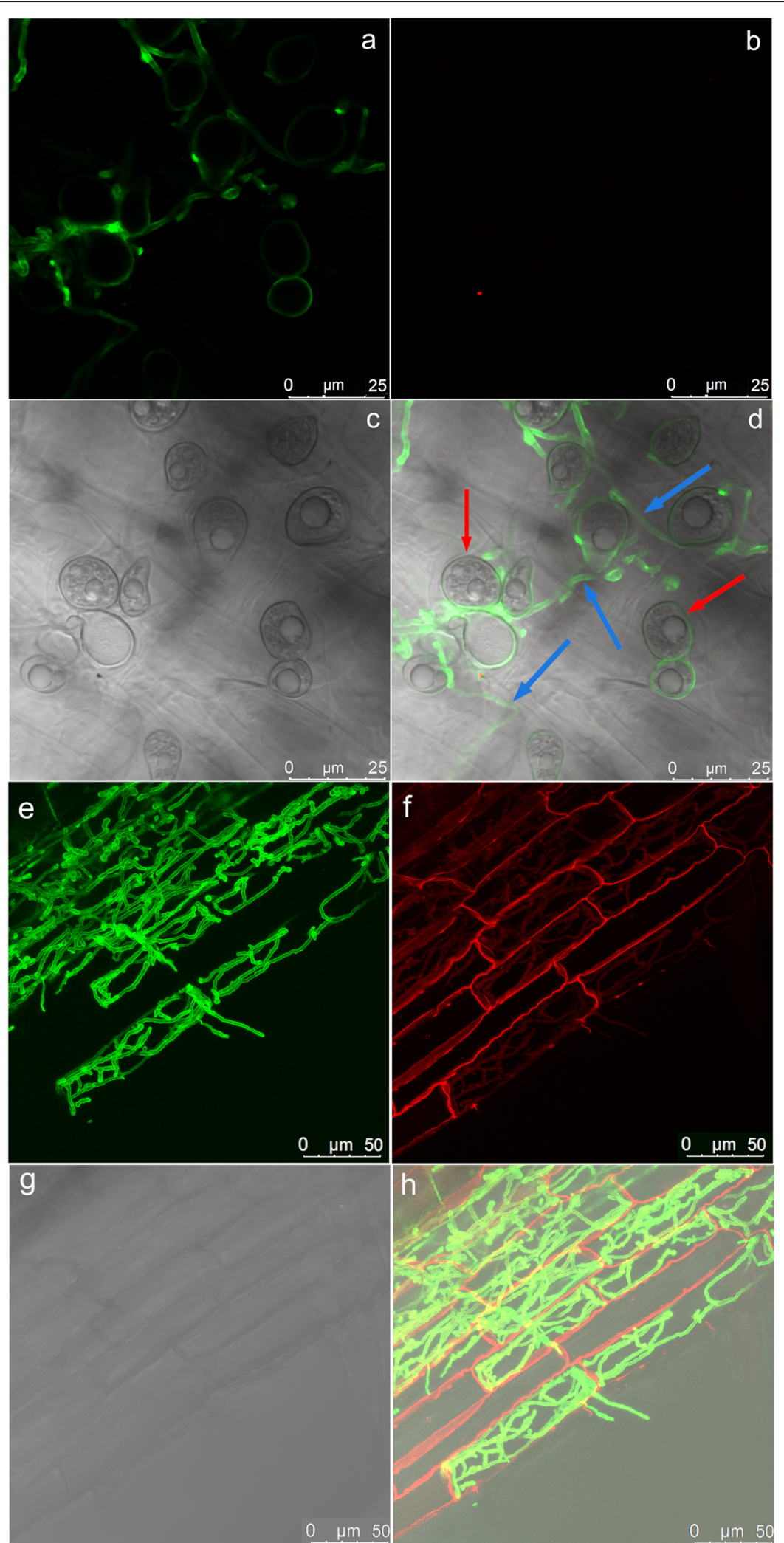

Fig. 2 (See legend on next page.) 
(See figure on previous page.)

Fig. 2 Colonization pattern of Serendipita indica (Si) on Brachypodium distachyon Bd21-3 roots. a-d Colonization at 4 DPI. a Fluorescence

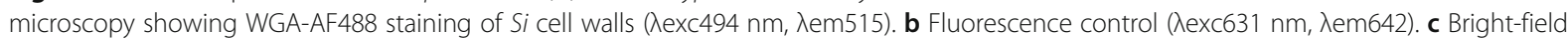
microscopy to visualize Si chlamydospores. d Overlay showing Si chlamydospores (red arrows), which have germinated and formed a hyphal network on the root surface (blue arrows). e-h Rhizodermal root colonization by Si at 4 DPI. e Fluorescence microscopy showing WGA-AF488

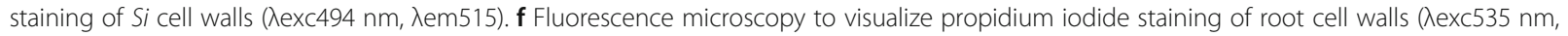

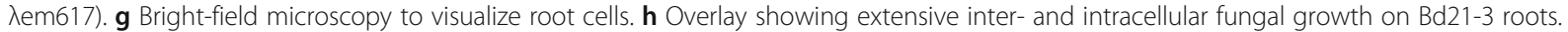
Imaging was done with a LEICA S8 confocal microscope (e-h: maximum projection; $z$-stack). For a-d, 1-week-old seedlings were inoculated with $5 \times 10^{5}$ chlamydospores per $\mathrm{ml}$ and subsequently grown on a plastic mesh over $0.5 \mathrm{X} \mathrm{MS}$; for $\mathbf{e}-\mathbf{h}$, Si-inoculated seedlings were grown on vermiculite:oil dri mix before harvesting at $4 \mathrm{DPI}$

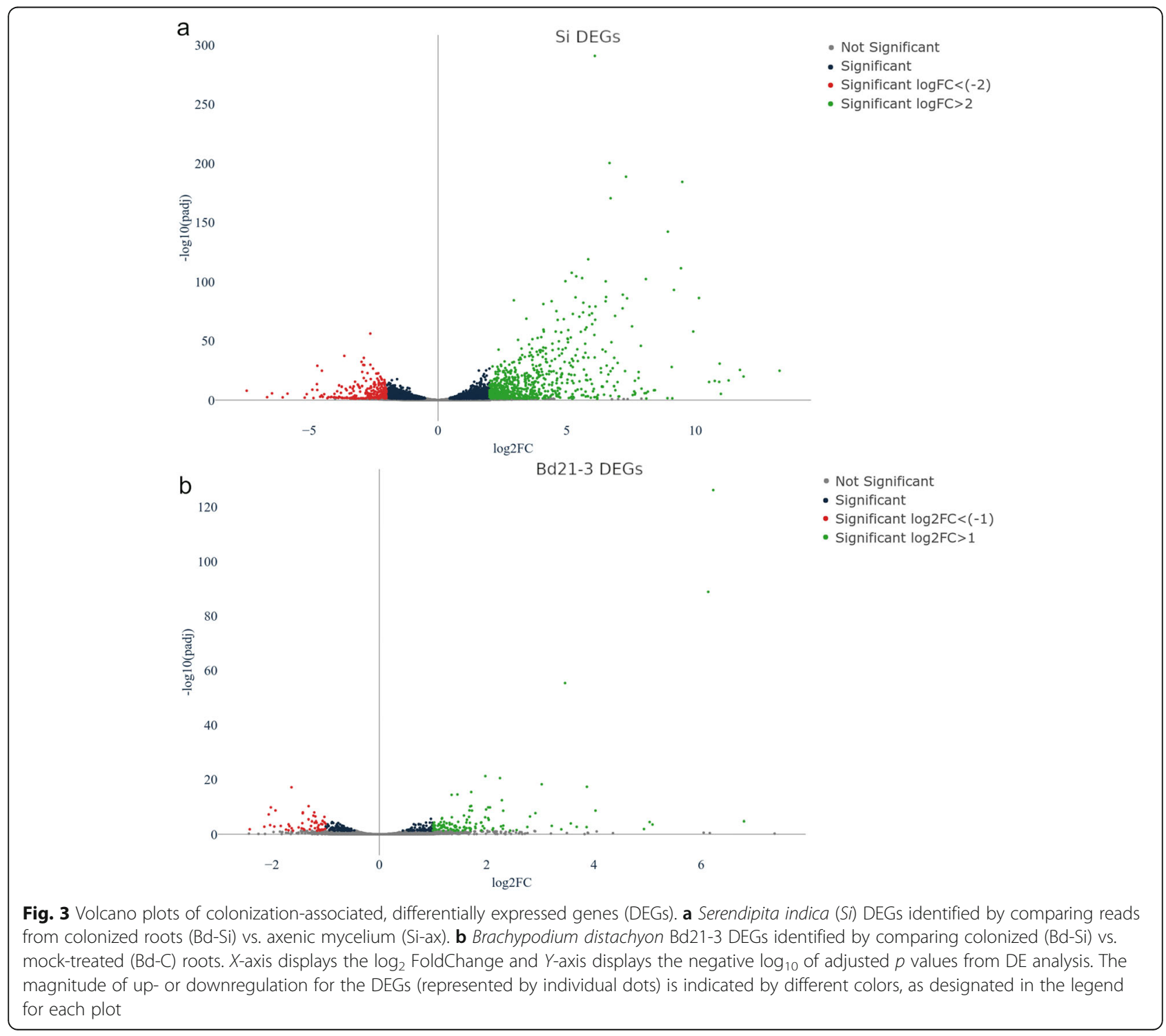


Table 1 Top 25 Serendipita indica (Si) differentially expressed genes (DEGs) during colonization (4 DPI)

\begin{tabular}{|c|c|c|}
\hline Gene & Description & $\log 2 \mathrm{FC}$ \\
\hline 1937_g (PIIN_04746) & Related to mismatch base pair and cruciform DNA recognition protein HMP1 & -5.84 \\
\hline 465_g (PIIN_02587) & Related to phenylalanine ammonia-lyase & -5.1 \\
\hline 281_g (PIIN_04449) & Probable succinate-fumarate transporter & -4.7 \\
\hline 1121_g (PIIN_02682) & Related to ADY2-protein essential for the acetate permease activity & -4.68 \\
\hline 7809_g (PIIN_07312) & Related to RTM1 protein & -4.52 \\
\hline 2544_g (PIIN_02778) & Probable ADH1-alcohol dehydrogenase I & -4.42 \\
\hline 4482_g (PIIN_08427) & Related to mixed-linked glucanase precursor MLG1 & -4.23 \\
\hline 4969_g (PIIN_02119) & Related to meiotic nuclear division protein 1 homolog & -3.54 \\
\hline 1859_g (PIIN_00204) & Probable thioredoxin & -3.45 \\
\hline 5786_g (PIIN_00305) & Probable DHA14-like major facilitator; ABC transporter & -3.41 \\
\hline 4465_g (PIIN_06089) & Putative mitochondrial carnitine O-acetyltransferase & -3.36 \\
\hline 1392_g (PIIN_11719) & Putative alkaline ceramidase 3 & -3.22 \\
\hline 8569_g (PIIN_01532) & Related to $\mathrm{Ca}^{2+}$-transport $\left(\mathrm{H}^{+} / \mathrm{Ca}^{2+}\right.$ exchange) protein & -3.21 \\
\hline 2933_g (PIIN_07440) & Related to monocarboxylate transporter 2 & -3.21 \\
\hline 758_g (PIIN_02772) & Probable TOM40-mitochondrial import receptor MOM38 & -3.19 \\
\hline 2855_g (PIIN_07067) & Related to l-asparaginase & -3.18 \\
\hline 5713_g (PIIN_07616) & Related to MFS transporter & -3.17 \\
\hline 3225_g (PIIN_08230) & Related to RSB1-integral membrane transporter & -3.11 \\
\hline 8602_g (PIIN_08742) & Putative maintenance of mitochondrial morphology protein 1 & -3.09 \\
\hline 917_g (PIIN_03155) & Related to YTP1 & -3.05 \\
\hline 6928_g (PIIN_00312) & Related to nitrogen metabolic regulation protein & -2.96 \\
\hline 6930_g (PIIN_00314) & Probable malate synthase & -2.94 \\
\hline 4348_g (PIIN_03103) & Putative ubiquitin-conjugating enzyme D4 & -2.9 \\
\hline 6400_g (PIIN_07801) & Probable acyl-CoA dehydrogenase short-branched chain precursor & -2.9 \\
\hline 5097_g (PIIN_04235) & Related to acyl-CoA dehydrogenase & -2.88 \\
\hline 5186_g (PIIN_09750) & Probable pectate lyase & 11.93 \\
\hline 8239_g (PIIN_02110) & Related to family 61 glucanase & 11.29 \\
\hline 3289_g (PIIN_05863) & Endo-1,4-beta-xylanase & 10.75 \\
\hline 7464_g (PIIN_04708) & Alpha-L-arabinofuranosidase & 10.14 \\
\hline 5322_g (PIIN_05889) & Endo-1,4-beta-xylanase & 10.14 \\
\hline 1898_g (PIIN_08141) & Glutathione S-transferase & 9.1 \\
\hline 5131_g (PIIN_02752) & Cellulose 1,4-beta-cellobiosidase & 8.93 \\
\hline 3537_g (PIIN_10118) & Carboxylic ester hydrolase & 8.83 \\
\hline 6726_g (PIIN_08399) & Probable alpha-galactosidase $B$ & 8.29 \\
\hline 4844_g (PIIN_06890) & Endo-1,4-beta-xylanase A & 7.9 \\
\hline 8585_g (PIIN_01553) & Probable beta-glucosidase & 7.88 \\
\hline 3597_g (PIIN_06117) & Related to endoglucanase B & 7.78 \\
\hline 5420_g (PIIN_07414) & Related to NACHTMD40 domain-containing protein & 7.64 \\
\hline 1875_g (PIIN_06862) & Rhamnogalacturonan acetylesterase & 7.62 \\
\hline 6520_g (PIIN_06360) & Endo-1,4-beta-xylanase $C$ & 7.53 \\
\hline 3290_g (PIIN_05862) & Probable endo-1,4-beta-xylanase A & 7.42 \\
\hline 3615_g (PIIN_11270) & Probable feruloyl esterase $C$ & 7.37 \\
\hline 5971_g (PIIN_04536) & Probable gEgh 16 protein & 7.3 \\
\hline 8031_g (PIIN_01484) & Related to CEL1 protein precursor & 7.2 \\
\hline
\end{tabular}


Table 1 Top 25 Serendipita indica (Si) differentially expressed genes (DEGs) during colonization (4 DPI) (Continued)

\begin{tabular}{|c|c|c|}
\hline Gene & Description & $\log 2 \mathrm{FC}$ \\
\hline 6665_g (PIIN_03039) & Probable beta-glucoside glucohydrolase & 7.15 \\
\hline 720_g (PIIN_06594) & Cellulose 1,4-beta-cellobiosidase & 7.08 \\
\hline 3514_g (PIIN_09664) & Glucose oxidase & 7.01 \\
\hline 290_g (PIIN_04439) & Related to peroxisomal short-chain alcohol dehydrogenase & 6.97 \\
\hline 6967_g (PIIN_00353) & Exocellobiohydrolase 3 & 6.7 \\
\hline 1893_g (PIIN_08147) & Probable glutathione S-transferase & 6.57 \\
\hline
\end{tabular}

DEGs are calculated as: colonized root vs. Si axenic culture exhibiting significant (padj. <0.05) down- or up-regulation, log ${ }_{2}$ FC (fold change) during colonization

signaling networks (Table 2 and Additional file 2: Table S3). In order to further validate our sequencing data, we confirmed the expression of five $\mathrm{Si}$ and five $\mathrm{Bd} 21-3$ DEGs from Tables 1 and 2 by RT-qPCR. Generally, the qPCR results show a similar fold change for the selected genes between the colonized root and the respective controls, compared to the mRNA-seq results (Additional file 2: Figure S5). Together, these results show that both organisms utilize a complex enzymatic arsenal to establish and control the symbiosis.

\section{Prediction of Si RNAi genes}

Since RNAi-mediated gene silencing has been documented in most but not all fungi [42], we assessed whether the Si-2020 genome encodes RNAi-related proteins with conserved domain architecture and homology to RNAi components in the model filamentous fungus Neurospora crassa [43]. Genes encoding predicted DCLs (G4U2H0, G4TBW9) with typical domains (dsRNA-binding, RNase III and helicase, [44]), QDE2-like proteins with PIWI domains typical of AGOs (G4TEK0, G4TLO4, [45]), an AGO-like protein (G4T5G9), and RdRPs (G4TNU7, G4TQP0) were identified and were expressed in axenic culture and Bd21-3-associated Si samples (Additional file 2: Table S5). Thus, the $S i$ genome is predicted to contain genes encoding critical components of the RNAi machinery. Based on these new data, and the earlier discovery that AGO and DCL families are expanded in the $B d$ genome [35], we decided to sequence the sRNAs of both organisms, in order to assess the role of RNAi-based regulation and communication in symbiosis.

\section{sRNA profiles undergo a substantial change at the onset of the Si-Bd symbiosis}

To evaluate how the mutualistic interaction affects the sRNA profiles in the colonized root and respective $S i$ and $B d$ controls, reads from $\mathrm{Bd}-\mathrm{C}, \mathrm{Bd}-\mathrm{Si}$, and Si-ax sRNA data sets were subjected to consecutive filtering steps (Additional file 2: Figure S6). This greatly reduced the number of raw reads to be analyzed and allowed us to distinguish between sRNAs with potential targets in the interacting organism (putative ck-sRNAs) and sRNAs with potential functions in the same organism (putative endogenous sRNAs) (Additional file 2: Table S6).

Analysis of sRNAs from the Bd-Si dataset revealed that the total number of putative ck-sRNAs exceeds that of endogenous sRNAs in both $\mathrm{Si}(786,732$ vs. 261,478$)$ and Bd21-3 (17 million vs. 1.6 million), but the converse is true for unique sRNAs $(36,163$ endogenous vs. 35,895 putative ck-sRNAs in $\mathrm{Si}$ and 483,352 endogenous vs. 286,198 putative ck-sRNAs in Bd21-3).

\section{Size distribution profiles of $\mathrm{Si}$ and Bd21-3 sRNAs}

Size distribution of sRNA reads from $\mathrm{Bd} 21-3$ and $S i$ during colonization, and the respective controls was then assessed. For putative endogenous Bd21-3 sRNAs, peaks at 21 and $24 \mathrm{nt}$ were identified, with the $24 \mathrm{nt}$ sRNAs exhibiting greater diversity than those of $21 \mathrm{nt}$ (Fig. 4a, b). These sizes are consistent with the expected peaks of RNAi-associated sRNAs in plants [46]. For putative endogenous Si sRNAs, a bimodal size distribution pattern was observed in the total fractions, with the first peak at $26 \mathrm{nt}$ and second at 29-30 nt (Fig. 4c, d). A smaller peak of $21 \mathrm{nt}$ long molecules was observed in the $\mathrm{Bd}-\mathrm{Si}$ but not $\mathrm{Si}$-ax samples, indicating that colonization affects the relative size distribution of $\mathrm{Si}$ sRNAs. Since previously identified ck-sRNAs range from 20 to $24 \mathrm{nt}[12,13]$, the size distribution of putative ck-sRNAs and corresponding reads in the control samples was assessed over a narrower window. Contrary to endogenous sRNAs, ck-sRNAs displayed no prominent peaks in the 20-24 nt window (Additional file 2: Figure S7).

Before sRNAs can guide RNAi-mediated gene silencing, they must be loaded onto AGO proteins and assembled into a RISC. Previously, Arabidopsis AGO proteins were shown to preferentially recruit sRNAs with specific $5^{\prime}$ termini [47]. Hence, we analyzed the $5^{\prime}$ terminal nt composition of Bd-C, Si-ax, and Bd-Si sRNAs. For unique putative endogenous and ck-sRNAs, the $5^{\prime}$ nt composition was relatively consistent except for the $24 \mathrm{nt} \mathrm{Bd} 21-3$ sRNAs, which exhibited a strong bias towards $5^{\prime}$ A (Additional file 2: Figure S8, Figure S9). The total sRNA 
Table 2 Top 25 Brachypodium distachyon (Bd) differentially expressed genes (DEGs) during root colonization (4 DPI)

\begin{tabular}{|c|c|c|}
\hline Gene & Description & $\log 2 \mathrm{FC}$ \\
\hline BdiBd21-3.2G0197800 & MYB-related transcription factor & -2.41 \\
\hline BdiBd21-3.5G0123400 & ABANWD induced protein & -2.14 \\
\hline BdiBd21-3.3G0280400 & Putative glycosyltransferase family 28 & -2.06 \\
\hline BdiBd21-3.3G0558500 & Putative steroid 17-alpha-monooxygenase & -2.03 \\
\hline BdiBd21-3.3G0660200 & AP2 domain-containing protein & -2.02 \\
\hline BdiBd21-3.1G0813200 & GRAS transcription factor & -1.96 \\
\hline BdiBd21-3.3G0264400 & Homologous to barley constans-like protein CO8 & -1.94 \\
\hline BdiBd21-3.4G0000100 & Fantastic four meristem regulator FAF & -1.84 \\
\hline BdiBd21-3.1G0416000 & Hydrophobic Protein $\mathrm{RCI} 2$ & -1.69 \\
\hline BdiBd21-3.1G0002200 & Ca2+-independent phospholipase A2 & -1.67 \\
\hline BdiBd21-3.1G0887100 & Putative pseudo-response regulator 7 & -1.64 \\
\hline BdiBd21-3.4G0311800 & Dirigent-like protein & -1.6 \\
\hline BdiBd21-3.1G0815300 & SPX domain-containing protein 3 & -1.43 \\
\hline BdiBd21-3.1G0972800 & Cold regulated protein 27 & -1.42 \\
\hline BdiBd21-3.4G0303000 & Putative protein kinase & -1.32 \\
\hline BdiBd21-3.2G0034900 & Putative sulfoquinovosyltransferase SQD2 & -1.21 \\
\hline BdiBd21-3.1G0281100 & SPX - domain containing protein 3 & -1.23 \\
\hline BdiBd21-3.1G0554700 & Anthranilate O-methyltransferase & -1.18 \\
\hline BdiBd21-3.1G0584400 & Peroxidase & -1.17 \\
\hline BdiBd21-3.5G0205300 & Putative calmodulin-dependent protein kinase & -1.15 \\
\hline BdiBd21-3.2G0749200 & Probable lipid transfer LTP2 & -1.13 \\
\hline BdiBd21-3.5G0303700 & Wound-induced protein & -1.1 \\
\hline BdiBd21-3.5G0024800 & Heat shock protein 90-1 & -1.07 \\
\hline BdiBd21-3.1G0399200 & bZIP transcription factor & -1 \\
\hline BdiBd21-3.1G0557300 & BURP domain protein & -0.93 \\
\hline BdiBd21-3.3G0203000 & Cupin-domain protein & 6.13 \\
\hline BdiBd21-3.1G0469800 & Glutathione S-Transferase & 5.09 \\
\hline BdiBd21-3.4G0405200 & Protein Hothead/ FAD binding & 4.93 \\
\hline BdiBd21-3.3G0354800 & Cytochrome P450 76C1 & 4.03 \\
\hline BdiBd21-3.3G0136300 & Proprotein convertase subtilisin/kexin & 3.87 \\
\hline BdiBd21-3.4G0068000 & Pathogenesis-related protein Bet v I family & 3.86 \\
\hline BdiBd21-3.1G0662500 & LRR receptor-like serine/theronine protein kinase & 3.57 \\
\hline BdiBd21-3.4G0556000 & Alcohol dehydrogenase & 3.39 \\
\hline BdiBd21-3.1G0772700 & Pathogenesis-related protein 1 (PR1) & 3.21 \\
\hline BdiBd21-3.4G0393500 & Putative chalcone synthase & 2.44 \\
\hline BdiBd21-3.3G0195800 & Tryptophan decarboxylase & 2.3 \\
\hline BdiBd21-3.4G0171000 & Multicopper oxidase & 2.28 \\
\hline BdiBd21-3.3G0639500 & Glycosyl hydrolase protein/Chitinase-related & 2.12 \\
\hline BdiBd21-3.1G0129100 & Potato inhibitor I family & 2.06 \\
\hline BdiBd21-3.2G0160100 & Pipecolate/sarcosine oxidase & 2.04 \\
\hline BdiBd21-3.4G0189100 & Putative LRR protein kinase & 1.99 \\
\hline BdiBd21-3.2G0418600 & WRKY transcription factor & 1.9 \\
\hline BdiBd21-3.4G0073800 & Thaumatin family protein & 1.8 \\
\hline BdiBd21-3.2G0545400 & LRR protein & 1.79 \\
\hline
\end{tabular}


Table 2 Top 25 Brachypodium distachyon (Bd) differentially expressed genes (DEGs) during root colonization (4 DPI) (Continued)

\begin{tabular}{lll}
\hline Gene & Description & log2FC \\
\hline BdiBd21-3.4G0121800 & Tryptophan biosynthesis protein & 1.71 \\
BdiBd21-3.4G0397700 & Serine/threonine protein kinase & 1.7 \\
BdiBd21-3.4G0026800 & Putative protein kinase & 1.69 \\
BdiBd21-3.2G0468100 & Peroxidase & 1.68 \\
BdiBd21-3.2G0600500 & Wall-associated receptor kinase & 1.6 \\
BdiBd21-3.2G0233800 & PGP-like phosphoglycoprotein auxin transporter & 1.58 \\
\hline
\end{tabular}

DEGs are calculated as: colonized root vs. mock-inoculated root exhibiting significant (padj. < 0.05) down- or upregulation, $\log _{2}$ FC (fold change) during colonization

fractions exhibited somewhat greater variability in $5^{\prime} \mathrm{nt}$ composition. Of the total Bd21-3 endogenous sRNAs, 24 nt molecules from colonized and non-colonized tissue showed a strong bias towards $5^{\prime} \mathrm{A}$, while $21 \mathrm{nt}$ molecules were biased towards a terminal U (Additional file 2: Figure S10), and 20 nt ck-sRNAs had a higher percentage of $5^{\prime}$ Cs (Additional file 2: Figure S11). Of the total endogenous $S i$ sRNAs, those from colonized samples generally had a stronger bias towards $5^{\prime}$ A than sRNA reads from Si-ax, especially at $26 \mathrm{nt}$ and $21 \mathrm{nt}$ (Additional file 2: Figure S10). A slightly higher percentage of $5^{\prime}$ As also was detected in total putative ck-sRNAs of $21 \mathrm{nt}$ (Additional file 2: Figure S11).

\section{Differentially expressed $S i$ and Bd21-3 sRNAs}

Analysis of unique plant sRNAs in $\mathrm{Bd}-\mathrm{C}$ vs. Bd-Si revealed that $63 \%$ of the putative endogenous sRNAs were exclusively present in Bd-C, $30 \%$ were exclusively in $\mathrm{Bd}-\mathrm{Si}$ and $7 \%$ were present in both (Fig. 5). For the reads from the putative ck-sRNA pipeline, $76 \%$ of the reads were exclusively present in $\mathrm{Bd}-\mathrm{C}, 13 \%$ were exclusive to $\mathrm{Bd}-\mathrm{Si}$, and $11 \%$ were found in both. Comparison between the unique fungal sRNAs in $\mathrm{Si}$-ax and $\mathrm{Bd}-\mathrm{Si}$ indicated that $98.1 \%$ of the putative endogenous sRNAs were exclusively present in axenic culture, $0.98 \%$ were exclusively found in $\mathrm{Bd}-\mathrm{Si}$, and $0.92 \%$ were in both. Similarly, from the putative ck-sRNA pipeline, $98.2 \%$ of

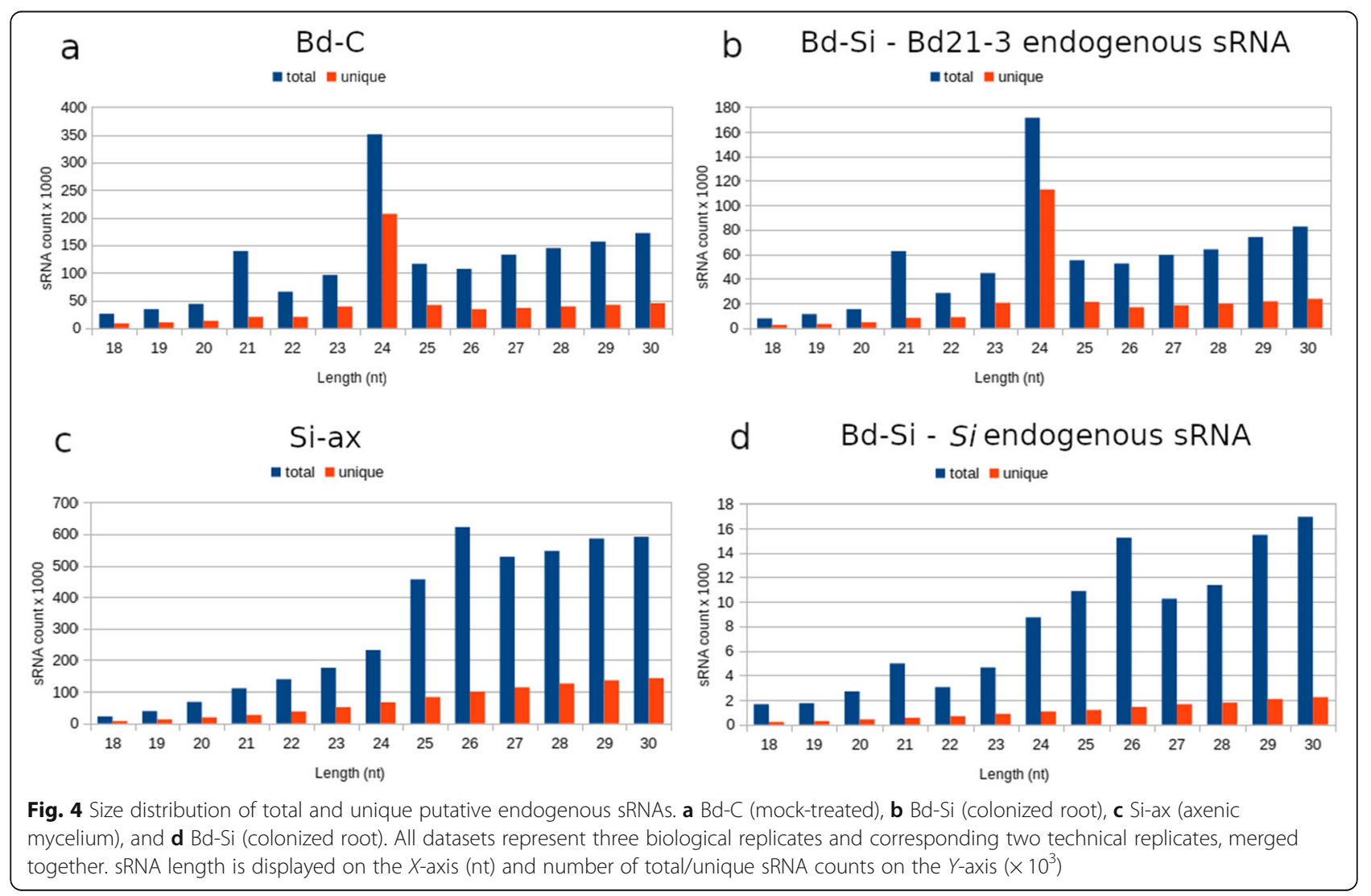




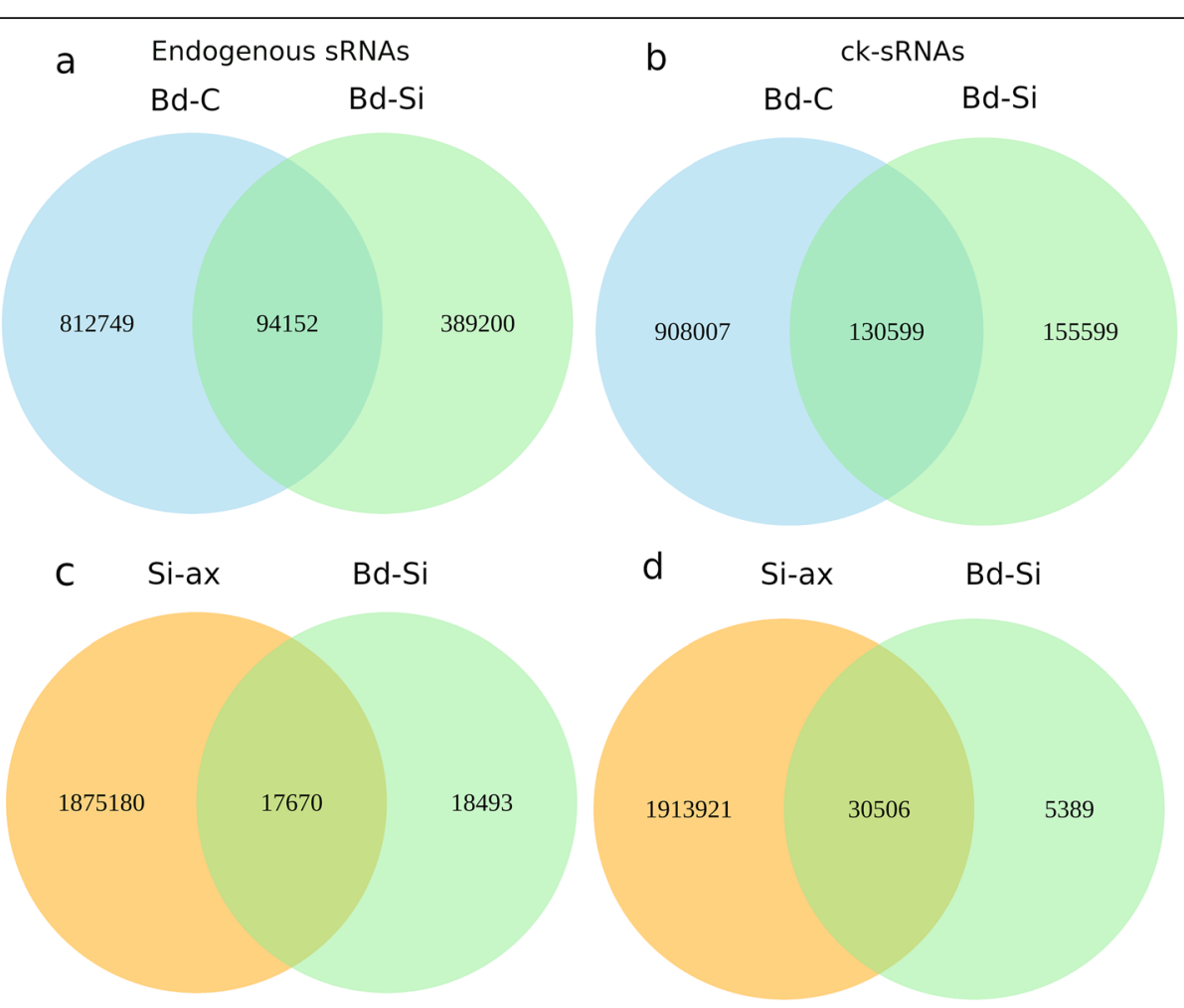

Fig. 5 Venn diagrams showing the sample-exclusive or communal presence of unique putative endogenous or ck-sRNAs. a putative endogenous sRNAs in Bd-C (mock-treated) vs. Bd-Si (colonized root), b sRNA reads in Bd-C vs. putative ck-sRNAs in Bd-Si, c putative endogenous sRNAs in Siax (axenic mycelium) vs. Bd-Si (colonized root), and $\mathbf{d}$ sRNA reads in Si-ax vs. putative ck-RNAs in Bd-Si

the sRNA reads were exclusive to the $\mathrm{Si}$-ax sample, 0.3 $\%$ were exclusive to $\mathrm{Bd}-\mathrm{Si}$, and $1.5 \%$ were present in both. Considering only the Si sRNAs in the Bd-Si sample, $51.1 \%$ of the putative endogenous ones and $15 \%$ of the putative ck-sRNAs are exclusively present in the colonized sample. Among Bd21-3 sRNAs in the Bd-Si sample, there are $80.5 \%$ putative endogenous sRNAs and 54.3\% ck-sRNAs exclusive for the colonized root. These data show that colonization induces many novel putative endogenous and ck-sRNAs in $\mathrm{Bd} 21-3$, and a smaller amount in $\mathrm{Si}$, due to fungal quantity in the colonized roots.

\section{Identification of $\mathrm{Bd} 21-3$ miRNAs during the $B d-S i$ interaction}

Using the ShortStack analysis tool, we identified Bd21-3 loci that correspond to putative endogenous sRNAs expressed during $\mathrm{Si}$ colonization. The DicerCall function indicated loci whose predominant sRNAs are 20-24 nt. Comparison of these sRNAs with miRBase identified 16 sRNA-generating loci that correlate to known miRNAs (Table 3). These miRNAs belong to highly conserved plant miRNA families that regulate growth and development $[33,34]$. We conducted the same analysis with $\mathrm{Si}$ sRNAs, but no predicted miRNA-like RNAs were identified in the colonized sample, possibly due to a lack of data about the fungal sRNA-generating loci.

\section{In silico target prediction of putative Si and Bd21-3 ck- sRNAs}

Since most examples of sRNA-based communication in plant-microbe interactions have the commonality of 21 nt long sRNAs that silence transcripts in the target organism [12, 13, 48], we predicted the targets of $21 \mathrm{nt}$ colonization-induced $S i$ and $B d$ putative ck-sRNAs and assessed their expression after colonization. Of 16,003 unique Bd21-3 targets predicted for 412 induced $21 \mathrm{nt} S i$ sRNAs, 49 were confirmed as downregulated at 4DPI. This represents $15.4 \%$ of all significantly changed genes in Bd21-3 during Si colonization. Some $89 \%$ of these transcripts are predicted as targets of $S i$ sRNAs that are expressed exclusively in colonized tissue or with $\log _{2} \mathrm{FC}$ $>1$. A representative set of sRNA-mRNA duplexes, chosen based on target identity and expression of target and sRNA, indicates that putative ck-sRNA targets in Bd21-3 are associated with transcription factor families, signaling pathways, and basal plant defense (Table 4, Additional file 2: Table S7).

To assess whether Bd21-3 generates ck-sRNAs that potentially target $S i$ genes, we searched for predicted targets of 329 Bd21-3 sRNAs (21 nt long) induced in Si- 
Table 3 Predicted miRNA-generating loci identified in Bd21-3 roots colonized by Serendipita indica

\begin{tabular}{lll}
\hline Locus & Predominant sRNA & Known miRNA \\
\hline Bd1:31073434-31073613 & UCGGACCAGGCUUCAUUCCCC & bdi-MIR166b \\
Bd2:10327043-10327213 & CUGCACUGCCUCUUCCCUGGC & bdi-MIR408 \\
Bd2:3991996-3992115 & UGACAGAAGAGAGUGAGCAC & bdi-MIR156e \\
Bd2:3992232-3992320 & UGACAGAGGGAGUGAGCAC & bdi-MIR156f \\
Bd2:3992444-3992557 & UUGACAGAAGAGAGUGAGCAC & bdi-MIR156g \\
Bd2:5570263-5570488 & CUUGGAUUGAAGGGAGCUCU & bdi-MIR159a \\
Bd3:1968409-1968509 & UCGCUUGGUGCAGAUCGGGAC & bdi-MIR168 \\
Bd3:33173606-33173746 & UCGGACCAGGCUUCAUUCCCC & bdi-MIR166c \\
Bd3:39150748-39150893 & GCUCACUUCUCUCUCUGUCACC & bdi-MIR156b \\
Bd3:4482899-4483000 & UUGACAGAAGAGAGUGAGCAC & bdi-MIR156c \\
Bd3:44836298-44836372 & AGAAGAGAGAGAGUACAGCCU & bdi-MIR529 \\
Bd3:7316295-7316393 & GGGCAACUCCUCCGUUGGCAGA & bdi-MIR399d \\
Bd4:1654850-1654943 & UGAAGCUGCCAGCAUGAUCUGA & bdi-MIR167e \\
Bd4:4893304-4893422 & CGGAGGUCAGGAUUCUACUGAUU & bdi-MIR9481b \\
Bd4:6029321-6029440 & UCUCGGACCAGGCUUCAUUCC & bdi-MIR166f \\
Bd5:18466111-18466202 & UGACAGAGAGAGUGAGCAC & bdi-MIR156d \\
\hline
\end{tabular}

Table 4 Examples of deduced duplexes of Serendipita indica sRNAs and their downregulated targets in Brachypodium distachyon

\begin{tabular}{|c|c|c|c|c|}
\hline sRNA name & sRNA Expression & Target transcript & Description & Transcript expression \\
\hline \multirow[t]{2}{*}{ SisRNA 1} & \multirow[t]{2}{*}{ NA } & BdiBd21-3.1G0887100.1 & Homologous to Arabidopsis pseudo-response regulator 3 and 7 & -1.63 \\
\hline & & BdiBd21-3.2G0440200.1 & Serine-carboxypeptidase-like 26-related & -0.81 \\
\hline SisRNA 2 & NA & BdiBd21-3.1 G0399200.1 & bZIP transcription factor & -1.00 \\
\hline SisRNA 3 & NA & BdiBd21-3.2G0288400.1 & LURP1-related & -1.20 \\
\hline SisRNA 4 & NA & BdiBd21-3.1G0475100.1 & Zinc-finger of the FCS-type & -1.00 \\
\hline SisRNA 5 & 0.13 & BdiBd21-3.1G0047100.1 & Nitrogen metabolic regulation protein NMR-related & -0.78 \\
\hline SisRNA 6 & 1.35 & BdiBd21-3.3G0750900.1 & Peroxygenase & -0.77 \\
\hline SisRNA 7 & NA & BdiBd21-3.1G0917100.1 & Enolase & -0.52 \\
\hline SisRNA 8 & NA & BdiBd21-3.4G0303000.1 & Protein kinase domain protein & -1.31 \\
\hline SisRNA 9 & NA & BdiBd21-3.1G0759800.1 & Carboxyl-esterase 15 related & -0.86 \\
\hline SisRNA 10 & NA & BdiBd21-3.1G0813200.1 & GRAS transcription factor & -1.95 \\
\hline SisRNA 11 & NA & BdiBd21-3.1G1017200.1 & Expansin-like related & -0.84 \\
\hline SisRNA 12 & NA & BdiBd21-3.3G0134800.1 & Copper transport protein ATOX1-related & -1.11 \\
\hline SisRNA 13 & 1.95 & BdiBd21-3.2G0288400.1 & LURP1-related & -1.20 \\
\hline SisRNA 14 & NA & BdiBd21-3.1G0917100.1 & Enolase & -0.52 \\
\hline \multirow[t]{2}{*}{ SisRNA 15} & NA & BdiBd21-3.4G0303000.1 & Protein kinase domain protein & -1.31 \\
\hline & NA & BdiBd21-3.1G0411900.1 & Serine-type carboxypeptidase activity (Blast2GO) & -0.82 \\
\hline SisRNA 16 & NA & BdiBd21-3.4G0507800.1 & MYB transcrition factor & -0.70 \\
\hline SisRNA 17 & NA & BdiBd21-3.1G0411900.1 & Serine-type carboxypeptidase activity (Blast2GO) & -0.82 \\
\hline SisRNA 18 & NA & BdiBd21-3.2G0269000.1 & Mannose-binding lectin family & -0.85 \\
\hline SisRNA 19 & NA & BdiBd21-3.3G0264400.1 & Homologous to barley CONSTANS-like protein CO8 & -1.93 \\
\hline SisRNA 20 & NA & BdiBd21-3.5G0237900.1 & Aquaporin transporter & -1.02 \\
\hline
\end{tabular}


colonized roots. Of 3,019 predicted unique $S i$ targets, 358 were confirmed as downregulated after colonization. This represents $12 \%$ of all significantly changed $S i$ genes. $35 \%$ of the $358 \mathrm{Si}$ transcripts are predicted to be targeted by Bd21-3 sRNAs exclusive to colonized tissue and an additional $27.6 \%$ are targeted by sRNAs that are highly upregulated in colonized tissue $\left(\log _{2} \mathrm{FC}>1\right)$. A set of sRNA-mRNA duplexes, selected with the same criteria as for the Si sRNA - Bd21-3 targets (Table 4), shows that predicted Bd21-3 ck-sRNAs have putative targets in $\mathrm{Si}$ which include proteins associated with nutrient acquisition, development of cell walls, hyphal networks, pathogenic fungal activities, fungal starvation, and signaling (Table 5, Additional file 2: Table S7). In order to confirm the expression of some of these sRNAs, we conducted stem-loop PCR and sRNA-specific sequencing on $10 \mathrm{Si}$ and $10 \mathrm{Bd} 21-3$-originating sRNAs from our $\mathrm{Bd}-\mathrm{Si}$ sample and Table S7. All Si and all Bd21-3 sRNAs were amplified in the stem-loop PCR. To verify the nature of the amplification products, a subset of four SisRNAs and three BdsRNAs were cloned and sent for Sanger sequencing, confirming the expected sRNA sequences (Additional file 2: Figure S12, original gel pictures in Additional file 3 and Additional File 4, sequencing results in Additional file 2: Table S8). Thus, predicted targets of putative ck-sRNAs within this system imply another layer of expression control within the mutualistic interaction.

\section{Discussion}

We established and studied the interaction between $\mathrm{Bra}$ chypodium distachyon-a model Pooideae plant with shared synteny to major cereal crops-and Serendipita indica-a beneficial endophyte with an exceptionally large host range. This particular combination of traits adorning the $B d-S i$ interaction has great translational value towards filling in the gaps in knowledge about plant symbioses, especially their transcriptomic and sRNA expression profiles and the significance of RNAi. We show that $S i$ colonizes $B d$, resulting in shoot growth promotion, earlier flowering, and improved grain development. In comparison, earlier studies characterizing

Table 5 Examples of deduced duplexes of Brachypodium distachyon sRNAs and their downregulated targets in Serendipita indica

\begin{tabular}{|c|c|c|c|c|}
\hline sRNA & sRNA expression & Transcript & Description of target transcript & Transcript expression \\
\hline BdsRNA 1 & NA & CCA68723 & Related to phenylalanine ammonia-lyase & -5.1 \\
\hline BdsRNA 2 & 1.43 & CCA69635 & Probable acetyl-CoA synthetase & -2.19 \\
\hline BdsRNA 3 & 0.04 & CCA72153 & Putative mitochondrial carnitine O-acetyltransferase & -2.94 \\
\hline BdsRNA 4 & 0.58 & CCA68099 & Probable protein required for hyphal anastomosis HAM2 & -1.38 \\
\hline BdsRNA 5 & 0.59 & CCA69082 & Related to serine/threonine-protein kinase & -1.65 \\
\hline BdsRNA 6 & 0.039 & CCA67801 & Probable isocitrate lyase & -2.34 \\
\hline BdsRNA 7 & 4.37 & CCA68918 & Probable ADH1-alcohol dehydrogenase I & -4.42 \\
\hline \multirow[t]{2}{*}{ BdsRNA 8} & NA & CCA77975 & Related to peroxisomal membrane protein 4 & -2.39 \\
\hline & & CCA68099 & Probable protein required for hyphal anastomosis HAM2 & -1.38 \\
\hline BdsRNA 9 & 0.029 & CCA73455 & Related to phosphoprotein phosphatase $2 \mathrm{C}$ & -0.89 \\
\hline \multirow[t]{3}{*}{ BdsRNA 10} & 1.39 & CCA72944 & Protein TOXD & -2.73 \\
\hline & & CCA72668 & Hypothetical protein & -1.68 \\
\hline & & CCA74115 & Probable nucleolar rRNA processing protein GAR1 & -0.93 \\
\hline BdsRNA 11 & 0.19 & CCA77931 & Related to iron transport protein & -2.4 \\
\hline BdsRNA 12 & 0.48 & CCA68412 & Related to ECM32-DNA dependent ATPase/DNA helicase B & -1.96 \\
\hline BdsRNA 13 & 1.06 & CCA75416 & Related to estradiol 17 beta-dehydrogenase 4 & -2.12 \\
\hline BdsRNA 14 & NA & CCA73650 & Related to chitinase & -1.37 \\
\hline BdsRNA 15 & 0.49 & CCA77900 & Related to LSB5-possible role in the regulation of actin cytoskeletal organization & -1.27 \\
\hline BdsRNA 16 & 0.62 & CCA69912 & Related to acyl-CoA dehydrogenase & -2.28 \\
\hline BdsRNA 17 & 0.88 & CCA70015 & Related to CAT1 & -1.84 \\
\hline BdsRNA 18 & NA & CCA68373 & Probable subtilisin-like serine protease & -0.91 \\
\hline \multirow[t]{2}{*}{ BdsRNA 19} & 1.38 & CCA72980 & Hypothetical protein & -2.59 \\
\hline & & CCA67021 & Probable VID27-involved in vacuole import and degradation & -0.93 \\
\hline BdsRNA 20 & 0.1 & CCA73174 & Related to ECM4-involved in cell wall biogenesis and architecture & -2.48 \\
\hline
\end{tabular}

sRNA expression was calculated as $\log _{2}$ (colonized/control) from normalized reads, NA stands for sRNAs expressed exclusively in the colonized sample; transcript expression is indicated as the $\log _{2}$ (colonized/control) FC 
the interaction between $S i$ and barley have demonstrated that fungal hyphae establish an interface with the root cell plasma membrane at an early colonization stage, followed by expansion of an extracellular hyphal network, intercellular growth, and intracellular penetration of cortical and rhizodermal cells [26]. Around 3 to 5 DPI, Si starts the switch from a biotrophic to a saprophytic lifestyle [26, 27]. Although this change involves intracellular hyphae extensively colonizing dead host cells and gradual digestion of cortical cell walls, the plant still benefits from the fungal presence. Consistent with these findings, our microscopic analyses confirmed proliferation of $\mathrm{Si}$ chlamydospores and both inter- and intracellular colonization of Bd21-3 cells in the root differentiation zone from 4 to 14 DPI. Detection of proliferating hyphae that were not wrapped in plasma membrane further suggests that $S i$ is colonizing dead surface plant root cells at 4 DPI $[25,26]$.

\section{Transcriptional changes detected during the $B d-S i$ interaction}

To investigate colonization of Bd21-3 by $\mathrm{Si}$, we analyzed Si DEGs in colonized vs. axenic mycelium samples. Gene ontology analysis indicated enrichment in genes involved in various metabolic and catalytic processes. DEGs with the greatest changes in expression play roles in plant cell wall degradation, carbohydrate metabolism and nutrient acquisition. These changes in nutritional reprogramming are to be expected, considering the different nutritional content that $S i$ has accessible in planta vs. axenic CM plates and a more detailed look into the roles of the changed genes unveils a typical switch of fungal lifestyle. Examples of upregulated $\mathrm{Si}$ genes involved in cell wall degradation include a probable Pectate lyase, Endo-1,4beta-xylanases, Cellulose 1,4-beta-cellobiosidase, and Rhamnogalacturonan acetylesterase. The genes encoding these hydrolytic enzymes, which have undergone expansion in the Si genome [49], are similar to those upregulated in $S i$ during saprophytic growth on autoclaved barley roots at 3 DPI and 5 DPI [22]. PiAMT1, encoding a high affinity ammonium transporter also was upregulated $(\log F C=3.35$; padj $<0.0001)$. Other upregulated genes encode enzymes involved in carbohydrate metabolism, including probable glucosidases, glucanase, and galactosidase. These proteins may modulate glucose concentration, which then regulates expression of some cell-wall degrading enzymes $[22,50]$. Some of the 174 putative effector protein-encoding genes also are differentially expressed during $\mathrm{Si}$ colonization of barley and Arabidopsis [22, 27]. Six of these proteins (Additional file 2: Table S4) contain the Si-specific DELD domain, which suggests that $S i$ utilizes a common protein effector arsenal to colonize various hosts. Considering highly downregulated Si DEGs, several encoded proteins are associated with adaption to nutrient availability ( $A c$ cumulation of dyads protein 2, ADY2; Succinate-fumarate transporter) and nutrient acquisition (Acyl-CoA dehydrogenase; Carnitine acetyltransferase, CRAT; Phenylalanine ammonia-lyase, PAL [51, 52];). Their reduced expression suggests ample nutrient availability at 4 DPI. Given the similarities in the $S i$ transcriptome during colonization of $B d$ and barley, we propose that these fungal-plant interactions follow a pattern, and that by 4 DPI, a network of plant-endophyte communication cues has initiated a tightly controlled transcriptional program, leading to a shift from biotrophic to saprophytic growth.

Roots of Bd21-3 plants also displayed substantial transcriptional reprogramming following $\mathrm{Si}$ colonization. Gene ontology term analysis indicated enrichment in genes involved in catalytic and oxidoreductionassociated processes. Bd21-3 DEGs exhibiting the greatest changes in expression between colonized and noncolonized plants are related to stress-response, defense, and plant development. Of the downregulated $\mathrm{Bd} 21-3$ genes, several encode proteins commonly associated with stress responses, including a peroxidase, a woundinduced protein, and a putative protein kinase. Additionally, members of the Heat-shock protein gene family [53] are commonly induced in $B d$ during abiotic stress and members of the Abscisic acid/water deficit stress (ABA/ WDS)-induced protein and the Rare cold inducible (RCI2) gene families enhance abiotic stress tolerance in various plant species $[54,55]$. Circadian clock and flowering regulation genes such as Pseudo-response regulator 7 (PRR7), Cold regulated protein 27 and Constans-like protein (CO8), also are downregulated during $S i$ colonization. While members of the PRR and CO protein families work together to control flowering time $[56,57]$, any influence on early flowering in Si-colonized Bd21-3 is unclear. Circadian clock-associated genes also regulate lateral root development in Arabidopsis [58]; whether $\mathrm{Si}$-induced changes in their expression influence root growth is unknown. Other downregulated development-associated DEGs include Fantastic four meristem regulator (FAF), which regulates shoot and root development [59], and putative Sulfoquinovosyltransferase (SQD2), which modulates seed setting and tiller development in rice [60]. Finally, several downregulated DEGs encode transcription factors, including MYB-related, GRAS, and bZIP.

In comparison, many of the upregulated Bd21-3 DEGs are associated with immune responses. Examples include genes encoding leucine-rich repeat (LRR) protein, a WRKY transcription factor, and thaumatin family protein. Increased expression of the defense gene Pathogenesis-related protein 1 (PR1) was similarly and transiently reported in Si-colonized Arabidopsis roots [61]. Upregulation of Glutathione S-transferase (GST) is consistent 
with the increased antioxidant capacity of Si-colonized plants, which provides protection against attack by necrotrophic pathogens [21, 62]. The upregulation of genes in other hormonal networks (PGP-like Phosphoglycoprotein auxin transporter) and redox processes (Multicopper oxidase) further suggests that $\mathrm{Si}$ colonization affects a range of signaling pathways.

\section{$B d$ miRNAs detected in the Bd-Si sample}

The role of miRNAs as regulators of gene expression in the Sebacinalean symbiosis is largely unexplored. One report showed that $\mathrm{Si}$ induces growth promotionassociated miRNAs in Oncidium orchid roots [63]. Analysis of putative endogenous Bd21-3 sRNAs expressed during $\mathrm{Si}$ colonization identified 16 miRNAs. Some of them have known targets in transcription factors associated with plant growth and development. For example, the bdi-MIR166 family targets mRNAs encoding Homeobox domain-leucine zipper transcription factors [64]. In Arabidopsis, repression of these transcription factors by the miR165/166 family modulates root growth, maintenance of the shoot apical meristem, and development of leaf polarity [65]. Plant-specific transcription factors encoded by Squamosa promoter-binding protein-like $(S P L)$ genes are the presumed targets of bdi-MIR156 and bdi-MIR529 [66]. In Arabidopsis, miR156-mediated downregulation of SPLs modulates developmental timing, lateral root development, branching, and leaf morphology [65]. Members of the MYB superfamily of transcription factors, which regulate many aspects of development, are the predicted targets of bdi-MIR159 [34]. Interestingly, miRNAs belonging to the miR159 and miR166 families in cotton are known ck-sRNAs that target virulence genes in Verticillium dahliae [13].

Other miRNAs identified in Bd21-3 include bdiMIR168, predicted to target $A G O 1$ [64], and two miRNAs that regulate nutrition: bdi-MIR399, which is upregulated in $B d$ by phosphate starvation $[64,67]$, whereas bdi-MIR408 influences copper levels [34, 68]. Additionally, bdi-MIR408 (BdsRNA 10) has predicted ck targets in three Si transcripts: CCA72944, CCA72668, and $C C A 74115$. Since various targets were predicted for bdi-MIR167 [34, 68] and no target was predicted for bdi-MIR9481, their endogenous functions in $B d$ are unclear. Interestingly, the miRNA families identified in our analysis, except bdi-MIR9481, also were detected in Sicolonized Oncidium [63]. Thus, this group of miRNAs may play an important role in reprogramming plant cells during Sebacinalean symbiosis establishment.

\section{Putative Si and Bd21-3 ck-sRNAs and their predicted targets}

To date, cross-kingdom RNAi has been demonstrated in pathogenic plant-fungal interactions [12, 13, 69], and while there are promising indications for its presence during plant-mycorrhiza interactions [36], whether it occurs in Si-plant associations is unknown. To investigate this possibility, we predicted targets for $21 \mathrm{nt}$ putative ck-sRNAs from $\mathrm{Si}$ and $\mathrm{Bd} 21-3$ and confirmed their downregulation during colonization. This analysis uncovered 358 downregulated $\mathrm{Si}$ transcripts that are the predicted targets of 228 unique Bd21-3 sRNAs. Crosskingdom RNAi-mediated downregulation of these targets might allow Bd21-3 to modulate $S i$ growth during colonization. For example, PAL, Acetyl-CoA synthetase, Carnitine acetyl transferase, Isocitrate lyase, and AcylCoA dehydrogenase, which are targeted by BdsRNA 1, BdsRNA 2, BdsRNA 3, BdsRNA 6, and BdsRNA 16 (Table 5), are involved in fungal nutrient acquisition [22, 55, 70, 71]. Genes with important homologs in pathogenic fungi also are predicted targets, including Subtilisin-like serine protease (BdsRNA 18) [72], Alcohol dehydrogenase 1 (BdsRNA 7) [73], and Phosphoprotein phosphatase 2C (BdsRNA 9) [74]. Targeting of Hyphal anastomosis-2 (HAM-2) by BdsRNA 8 and BdsRNA 4 may provide another mechanism for controlling fungal growth, as HAM-2 is required for hyphal fusion in $N$. crassa [75]. Similarly, targeting of Chitinase (BdsRNA 14) may help control Si growth.

Concurrently, we identified 49 downregulated Bd21-3 mRNAs that are the predicted targets of 63 unique Sigenerated ck-sRNAs. Downregulation of these target genes via cross-kingdom RNAi might facilitate $S i$ growth during colonization. For example, Mannose-binding lectin (targeted by SisRNA 18) belongs to a family of defense-related genes whose products trigger immune responses following pathogen recognition [76]. SisRNA 8 and SisRNA 15 target a protein kinase domain/LRR gene (BdiBd21-3.4G0303000.1) that may belong to the LRR receptor kinase family, which regulates defense and developmental-related processes [77]. Transcripts encoding serine-carboxypeptidase-like (SCPL) proteins BdiBd21-3.2G0440200.1 and BdiBd21-3.1G0411900.1 (targeted by SisRNA 1 and SisRNA 15) are associated with defense against (a)biotic stresses in monocots [78]. Members of various transcription factors families also were identified as predicted targets (MYB by SisRNA 16, bZIP by SisRNA 2, and GRAS by SisRNA 10). These families are associated with (a)biotic stress responses, as well as plant growth and development [79-81]. Lastly, transcripts for proteins involved in circadian clock and flowering regulation (BdiBd21-3.1G0887100.1 and BdiBd21-3.3G0264400.1 [56];) are the presumed targets of SisRNA 1 and SisRNA 19. Together, these findings suggest that $\mathrm{Si}$-derived ck-sRNAs may promote fungal colonization by targeting signaling processes associated with plant development and responses to (a)biotic stresses. 
In combination with earlier studies on $B d$ RNAi proteins [35] and $B d$ interaction with the pathogen Magnaporthe oryzae [82], the in silico analyses presented here suggest that $\mathrm{Si}$ and $\mathrm{Bd}$ contain functional RNAi components and that both organisms generate ck-sRNAs, which potentially modulate this mutualistic interaction. However, further studies are necessary to validate crosskingdom RNAi in a Sebacinalean symbiosis. Namely, degradome analysis is needed to confirm target degradation and evidence that $\mathrm{Bd} 21-3$ and $\mathrm{Si}$ AGOs associate with sRNAs expressed by the interacting organism is necessary for confirmation of cross-kingdom RNAi.

\section{Conclusions}

We report that $\mathrm{Bd} 21-3$ and $S i$ form a mutualistic symbiosis with a promoting effect on plant yield and development, accompanied by changes in gene expression in both organisms, including putative protein $\mathrm{Si}$ effectors and RNAi-related genes. sRNA profiles of both organisms also changed, indicating that this model system will provide important insights into the multiple layers of regulation and interaction between beneficial fungi and cereal hosts. Within the broader scope of plant-mutualist interactions, we show that detection of putative RNAiinvolved sRNAs in an interaction highly benefits from simultaneous transcriptome analysis and indicate an involvement of sRNA-based regulation in defense responses, nutritional reprogramming, and colonization maintenance. Alongside other experimental approaches in plant-microbe interactions (eg. sRNA uptake studies [83]), developing a deeper understanding of the communication mechanisms that modulate mutualistic interactions is highly relevant for establishing robust growth promotion and protection strategies in crops.

\section{Methods}

\section{$B d$ and Si cultivation and inoculation}

The seeds of Brachypodium distachyon $(B d)$ line Bd21-3 (gift from R. Sibout, INRA Versailles, France) were surface sterilized ( $3 \%$ active chlorine, sodium hypochlorite solution) for $15 \mathrm{~min}$, washed three times, and placed on half-strength MS [84] medium in dark at $4{ }^{\circ} \mathrm{C}$ for 2 days and then 7 days at $24{ }^{\circ} \mathrm{C}$ and $16 \mathrm{~h} \mathrm{light} / 8 \mathrm{~h}$ dark cycle $\left(47 \mu \mathrm{mol} \mathrm{m}^{-2} \mathrm{~s}^{-1}\right.$ photon flux density). Serendipita indica (Si) (IPAZ11827, Institute of Phytopathology, Giessen, Germany) was grown on complete media plates (CM [85]) at $23^{\circ} \mathrm{C}$ in dark for $4-5$ weeks.

For inoculation, $\mathrm{Si}$ mycelium was collected in $0.002 \%$ aqueous Tween 20 solution, filtered (Miracloth, Calbiochem), and pelleted by centrifugation (10 $\min / 4000 \mathrm{rpm} / 20^{\circ} \mathrm{C}$ ) twice. Chlamydospore concentration of $5 \times 10^{5}$ conidia $\mathrm{ml}^{-1}$ in $0.002 \%$ Tween 20 solution was used to inoculate 7-day-old plant seedlings for $2-3 \mathrm{~h}$. Control plants were mock treated with the $0.002 \%$ Tween 20 solution for the same time. Grain yield analyses were done on mature plants grown on soil (F-E type LD 80, Fruhstorfer Erde, Germany) under $16 \mathrm{~h}$ light $\left(160 \mu \mathrm{mol} \mathrm{m}^{-2} \mathrm{~s}^{-1}\right.$, $22^{\circ} \mathrm{C}$ ) and $8 \mathrm{~h}$ dark $\left(18{ }^{\circ} \mathrm{C}\right)$ conditions at $60 \%$ relative humidity for 1 month, and then greenhouse conditions until seed maturity. Number of spikelets was assessed after 2 months. Shoot biomass was assessed 3 weeks after inoculation of seedlings grown on a mixture $(2: 1, \mathrm{v} / \mathrm{v})$ of vermiculite (Deutsche Vermiculite $\mathrm{GmbH}$ ) and oil dri (oil binder Typ III R Coarse grain, Damolin, Mettmann, Germany) under comparable conditions as for grain yield, and fertilized every 3 days with an aqueous solution of Wuxal Super NPK-8/8/6 (1:10 v/v; Haug, Düsseldorf, Germany). Samples for RNA-seq, RT-qPCR, stem-loop PCR, and microscopy were also grown under these conditions. To assess growth promotion in $S i$ inoculated $B d$ relative to the control, we used the pairwise $t$ test or the Mann-Whitney-Wilcoxon test on each of the three repetitions of experiments, after checking for normality and homogenous variances. Benjamini-Hochberg correction for multiple testing was used to correct the $p$ values and the significance asterisks were assigned to the average $\mathrm{p}$-value as follows: * for $p \leq$ 0.05 , *** for $p \leq 0.001$, and ${ }^{* * * *}$ for $p \leq 0.0001$.

\section{Microscopy}

Following $S i$ inoculation, one-week-old seedlings were grown on plastic mesh $(\sim 90 \mu \mathrm{m})$ placed over halfstrength MS medium or on vermiculite/oil dri prior to assessing root colonization. Si was visualized with the chitin-specific dye WGA-AF 488 (wheat germ agglutinin; Molecular Probes, Karlsruhe, Germany), as described in Deshmukh et al. (2006) [26], with boiling in $\mathrm{KOH}(10 \%)$ for $30 \mathrm{~s}$, prior to incubation in phosphate-buffered saline (PBS, pH 7.4). Root cells were visualized by incubating with propidium iodide $\left(10 \mu \mathrm{g} \mathrm{ml}^{-1}\right)$ for $10 \mathrm{~min}$ and washing with sterile water. Confocal laser scanning microscopy was done (TCS SP8 microscope, Leica, Bensheim, Germany) and the Leica LAS $\mathrm{X}$ software was utilized for visualization and maximum ( $z$-stack) projections.

\section{Resequencing, assembly, and annotation of the Si genome}

The MasterPure Yeast DNA Purification Kit (Epicentre, Illumina) was used to extract genomic DNA from 4-week-old axenic $S i$ cultures. The $S i$ genome was resequenced, assembled [86], and annotated as described [87], whereby a MinION sequencing library 
was prepared using the Nanopore Rapid DNA Sequencing kit. Sequencing was performed on an Oxford Nanopore MinION Mk1b sequencer using a R9.5 flow cell. Additionally, sequencing of an Illumina Nextra XT library was performed on the MiSeq platform (Illumina; $2 \times 300 \mathrm{bp}$ paired-end sequencing, v3 chemistry). Adapters and low-quality reads were removed by an in-house software pipeline prior to polishing [88]. MinKNOW (v1.13.1, Oxford Nanopore Technologies) was used to control the run with the $48 \mathrm{~h}$ sequencing run protocol, and base calling was performed offline using albacore (v2.3.1, Oxford Nanopore Technologies). The assembly was performed using Canu v1.6 ([89], default settings). The resulting contigs were polished with Illumina short read data using Pilon [90] for eight iterative cycles. BWA-MEM [91] was used for read mapping in the first four iterations and Bowtie2 v2.3.2 [92] in the second set. Gene prediction was performed with GeneMark-ES 4.3.3. ([38], default settings). Predicted genes were functionally annotated using a modified version of the genome annotation platform GenDB 2.0 [39] for eukaryotic genomes [40]. RNAi-associated proteins were predicted by searching the proteome [22] for typical domain structure and highest homology to Neurospora crassa RNAi proteins (NC12 genome assembly [93]). A modified version of the pipeline from Rafiqi et al. (2013) [41] was used to predict protein effectors. After identifying proteins with signal peptides (signalp-4.1 [94]), those predicted as transmembrane helix proteins (tmhmm [95]), mitochondrial proteins (target-1.1 [96]), and cell wall hydrolysis-associated proteins were removed. For comparative analysis of the $\mathrm{Si}$ (Si-2020 and DSM11827 ASM31354 v.1 [22]), Serendipita vermifera [97] and Laccaria bicolor [98] genomes, software platform EDGAR 2.3 [99] was used.

\section{RNA extraction, library preparation, and mRNA/sRNA sequencing}

Roots inoculated with $\mathrm{Si}(\mathrm{Bd}-\mathrm{Si})$ or mock-inoculated (Bd-C), as described above, were grown for 4 days and pooled (three roots per sample). Si mycelium and spores were collected from 4-week-old axenic cultures grown on $\mathrm{CM}$ medium. All samples in triplicates were shock frozen, stored at $-80^{\circ} \mathrm{C}$, and ground in liquid $\mathrm{N}_{2}$. Total RNA was isolated using the ZymoBIOMICS RNA Mini Kit (Zymo Research, USA), quantified with DropSense16/Xpose (BIOKÉ, Netherlands), and analyzed with an Agilent 2100 Bioanalyzer Nano Chip (Agilent, Germany). RNA Clean and Concentrator 25 and 5 kits (Zymo Research) were utilized to separate total RNA into fractions: $17-200 \mathrm{nt}$ and $>200 \mathrm{nt} .1 .5 \mu \mathrm{g}$ of the larger fractions were processed for mRNA library preparation (TruSeq Stranded mRNA protocol, Illumina, USA). Fragment Analyzer Automated CE System (Advanced Analytical Technologies, Austria) determined the quality of the generated polyA mRNA libraries. Quantity and quality of the smaller RNA fractions were assessed with the Qubit fluorometer (Invitrogen, Germany) and Agilent 2100 Bioanalyzer Pico Chip. sRNA library preparation was done with $50 \mathrm{ng}$ of RNA (TruSeq Small RNA Library Prep, Illumina) and size selection with the BluePippin (Sage Science, USA) for fragments between 140 and $160 \mathrm{nt}$ (15-35 nt without adapters) applied. Sequencing was accomplished on the Illumina HiSeq 1500.

\section{Transcriptome analysis}

Raw reads from mRNA sequencing [100] were submitted to quality check using FastQC [101] and aligned to the Bd21-3 v1.1 (DOE-JGI, http://phytozome.jgi.doe.gov/ [102]) or resequenced $\mathrm{Si}(\mathrm{Si}-2020)$ genomes with HISA T2 [103]. An intron length of 20-2000 nt was allowed for Si [104] and 20-10,000 nt for Bd21-3 [105]. The reads were counted using HTSeq-count [106], differential gene expression was performed with DESeq2 [107], and gene enrichment analysis with AgriGO v.2 [108], with reference $B d 21$ setting for $B d 21-3$ (Bd 21 synonyms) and a customized background for Si. Volcano plots were generated using plotly [109] and ggplot2 [110] R [111] libraries. Gene descriptions were obtained from the organism annotations or Blast2GO [112].

\section{sRNA analysis and prediction of putative endogenous and ck-sRNAs}

Raw reads from sRNA sequencing [113] were submitted to FastQC [101] and adapter trimming [114]. Bowtie [115] was used for alignment as detailed in Additional file 2: Fig. S6. The resequenced $\mathrm{Si}$ genome was used for alignments of fungal origin. tRNA/rRNA sequences were downloaded from RNAcentral ([116], EMBL-EBI). Putative endogenous sRNA reads were submitted to ShortStack [117]. For filtering putative ck-sRNAs, a previously established pipeline [118] was utilized. Reads were normalized to the total number of mapped reads for a single genome and reads per million (RPM) and $\log _{2}$ (colonized/mock-treated) values calculated. Thus, a sRNA read was selected as a putative ck-sRNA if it was present exclusively or at a higher quantity (i.e., induced) in the colonized vs. control sample. Putative ck-sRNAs were submitted to psRNAtarget [119]. Since the separation of sRNA and mRNA fractions from each biological sample was facilitated, we checked for downregulation of mRNAs corresponding to predicted sRNA target genes within the DEGs. Transcriptomes used for these predictions were Bd 21-3 v1.1 (DOE-JGI, http://phytozome.jgi. doe.gov/ [102]) and Si DSM11827 ASM31354 v.1 [22]. 
Venn diagrams were generated using the VennDiagram $\mathrm{R}$ package [120].

\section{Quantitative real-time PCR and stem-loop PCR for validation of sequencing results}

To validate gene expression detected in the sequencing, we used quantitative real-time PCR (qRT-PCR). RNA extraction from mock treated and $\mathrm{Si}$ inoculated Bd21-3 roots, as well as $\mathrm{Si}$ axenic cultures, under the same conditions as explained above for the sequencing, was done with TRIzol (Thermo Fisher Scientific, Waltham, MA, USA), cDNA synthesized using qScriptTM cDNA kit (Quantabio, Beverly, MA, USA) and $10 \mathrm{ng}$ of cDNA used as template in the QuantStudio 5 Real-Time PCR system (Applied Biosystems), with SYBR ${ }^{\circ}$ green JumpStart Taq ReadyMix (Sigma-Aldrich, St. Louis, MO, USA). Each sample had three technical replicates. Primers used for these amplifications are listed in Table S9 (Additional file 2: Table S9). Transcript levels were calculated using the 2- $\Delta \Delta C$ t method [121], relatively to BdUbi4-3 for Bd21-3 and Si ITS sequence for Si.

For the identification of sRNAs in the interaction of $S i$ with Bd21-3 stem-loop RT-PCR was employed [122]. cDNA was synthesized from DNase I-treated total RNA extracted from $\mathrm{Si}$ axenic culture or inoculated Bd21-3 roots. The folding of the hairpin primer was performed according to Kramer (2011) [123]. For each stem-loop reaction, six hairpin primers were multiplexed in a 20 $\mu \mathrm{L}$ reaction using the Revertaid RT enzyme according to the manufacturer's instructions (Thermo Scientific). For primer annealing, the reaction was incubated for $30 \mathrm{~min}$ at $16^{\circ} \mathrm{C}$ followed by an extension step at $42^{\circ} \mathrm{C}$ for 30 min. The reaction was stopped at $85^{\circ} \mathrm{C}$ for $5 \mathrm{~min}$. cDNA was stored at $-80^{\circ} \mathrm{C}$ until further use. Endpoint PCR was performed using an universal stem-loop primer and specific sRNA primer (Additional file 2: Table S10) under the following conditions: initial denaturation at $95^{\circ} \mathrm{C}$ for $5 \mathrm{~min}$ followed by 35 cycles: $95^{\circ} \mathrm{C}$ for $30 \mathrm{~s}$, primer annealing at $60^{\circ} \mathrm{C}$ for $30 \mathrm{~s}$, and extension at $72^{\circ} \mathrm{C}$ for $30 \mathrm{~s}$. PCR products were separated by gel electrophoresis on a $2 \%(w / v)$ agarose gel. To obtain sequence information of the amplified sRNAs of the stem-loop reaction, PCR products were purified and cloned into the pGEM $^{\circ}$-T Easy Vector Systems (Promega, Madison, WI, USA) following the manufacturer's instructions. From each cloned sRNA, six colonies were further analyzed by Sanger sequencing using a M13 reverse primer.

\section{Abbreviations}

AGO: Argonaute; Bd: Brachypodium distachyon; Bd-C: Mock-inoculated Bd root sample; Bd-Si: Si-inoculated Bd root sample; BdsRNA: Brachypodium distachyon-derived sRNA; ck-sRNA: Cross-kingdom sRNA; DCL: Dicer-like; DEG: Differentially expressed gene; DPI: Day(s) post inoculation; FC: Fold change; miRNA: MicroRNA; nt: Nucleotide; RdRP: RNA-dependent RNA polymerase; RNAi: RNA interference; Si: Serendipita indica; Si-ax: Si axenic culture sample; SisRNA: Serendipita indica-derived sRNA; sRNA: Small RNA

\section{Supplementary Information}

The online version contains supplementary material available at https://doi. org/10.1186/s12915-021-01104-2.

Additional file 1. Supporting individual data values displayed in Figure $1 \mathrm{a}-\mathrm{c}$ and Additional File 2: Figure S5.

Additional file 2: Fig. S1. Serendipita indica (Si) colonization has an effect on Brachypodium distachyon (Bd) root structure. Fig. S2. Progress of Serendipita indica (Si) spore proliferation during colonization of Brachypodium distachyon Bd21-3. Fig. S3. Comparison of the resequenced Serendipita indica (Si) genome to the 2011 assembly. Fig.S4. Comparison of the resequenced Serendipita indica (Si) genome to Serendipita vermifera and Laccaria bicolor. Fig. S5. qRT-PCR confirmation of DEGs identified during mRNA sequencing. Fig. S6. Filtering pipelines applied in the analysis. Fig. S7. Size distribution of total and unique putative ck (cross-kingdom) -sRNAs. Fig. S8. Percentage distribution of the $5^{\prime}$ terminal nucleotide in unique putative endogenous sRNAs. Fig. S9. Percentage distribution of the $5^{\prime}$ terminal nucleotide in unique putative cksRNAs. Fig. S10. Percentage distribution of the $5^{\prime}$ terminal nucleotide in total putative endogenous sRNAs. Fig. S11. Percentage distribution of the $5^{\prime}$ terminal nucleotide in total putative ck-sRNAs. Fig. S12. Stem-loop PCR (gel electrophoresis) of some $\mathrm{Si}$ and $\mathrm{Bd} 21-3$ sRNAs expressed in the Bd-Si sample. Table S1. Quantification of identified features in the resequenced genome of Serendipita indica (Si). Table S2. Total reads from the Bd-C (mock-treated), Bd-Si (colonized root) and Si-ax (axenic culture) samples and their alignment rate (HISAT2) to the corresponding ge-

nomes. Table S3. Significant gene ontology terms of molecular function in the differentially expressed genes (DEGs) datasets. Table S4. Predicted protein effectors identified in the resequenced Serendipita indica (Si) genome. Table S5. Candidate RNAi machinery proteins predicted from the resequenced Serendipita indica (Si) genome. Table S6. Total and unique reads for filtered sRNAs from Bd-C (mock-treated), Bd-Si (colonized root) and Si-ax (axenic culture). Table S7. Sequences of putative sRNAs in Tables 4 and 5. Table S8. sRNA sequences after stem-loop PCR amplification. Table S9. Primers used for qRT-PCR (Figure S5). Table S10. Primers used for stem-loop PCR and sequencing (Figure S12, Table S8).

Additional file 3. Uncropped gel picture annotated in Additional file 2: Figure S12a.

Additional file 4. Uncropped gel picture annotated in Additional file 2: Figure S12b.

\section{Acknowledgements}

We thank Elke Stein, Dagmar Biedenkopf, Ute Micknass and Christina Birkenstock for technical assistance. We thank Dr. John Vogel and the DOE$\mathrm{JGl}$ for permission to use the Bd21-3 genome under early access conditions. Brachypodium distachyon Bd21-3 is a gift of R. Sibout, INRA Versailles. We are very thankful to D'Maris Dempsey for her assistance in preparation of the manuscript.

\section{Authors' contributions}

EŠ, SZ, DW, and KHK wrote the text and drafted the figures. EŠ and SZ designed and conducted the establishment experiments, EŠ, SZ, TB, DW, L, and JK conducted the RNAseq and genome resequencing experiments and analyzed the data. SN and JS conducted the stem-loop PCR experiments and sequencing analysis. $\mathrm{Jl}$ and $\mathrm{JT}$ performed microscopy in sterile conditions. All authors read and approved the final manuscript.

\section{Funding}

This work was supported by the Deutsche Forschungsgemeinschaft (DFG), Research Training Group (RTG) 2355, and Research Unit FOR5116 to KHK. We gratefully acknowledge the bioinformatics support of the BMBF-funded project Bielefeld-Gießen Center for Microbial Bioinformatics-BiGi (grant number 031A533) within the German Network for Bioinformatics Infrastructure (de.NBI). Open Access funding enabled and organized by Projekt DEAL.

\section{Availability of data and materials}

All data generated or analyzed during this study are included in this published article, its supplementary information files (Additional files 1, 2, 3 and 4) and publicly available repositories. mRNA and sRNA-seq of 
Brachypodium distachyon roots inoculated with Serendipita indica datasets are available in the ArrayExpress database at EMBL-EBI (www.ebi.ac.uk) arrayexpress) under accession numbers E-MTAB-10649 and E-MTAB-10650, respectively. The genome assembly data for Serendipita indica resequencing study is available in the European Nucleotide Archive (ENA) at EMBL-EBI under accession numbers: assembly GCA_910890315 and study PRJEB45884 (https://www.ebi.ac.uk/ena/browser/view/PRJEB45884).

Additional publicly available datasets have been accessed from the corresponding European Nucleotide Archive accessions and EnsemblFungi: Serendipita indica 2011 genome (GCA_000313545.1) [22], NC12 of Neurospora crassa (GCA_000182925.2) [93]. Serendipita vermifera subsp. bescii [97] has been accessed from JGI MycoCosm (https://mycocosm.jgi.doe.gov/ Sebvebe1/Sebvebe1.home.html), as was the Laccaria bicolor genome ([98], https://mycocosm.jgi.doe.gov/Lacbi2/Lacbi2.home.html).

The Bd21-3 v1.1 genome [102] was accessed under early access conditions and these sequence data were produced by the US Department of Energy Joint Genome Institute - DOE-JGl, http://phytozome.jgi.doe.gov/.

\section{Declarations}

\section{Ethics approval and consent to participate}

Not applicable.

\section{Consent for publication}

Not applicable.

\section{Competing interests}

The authors declare that they have no competing interests.

\section{Author details}

${ }^{1}$ Institute of Phytopathology, Centre for BioSystems, Land Use and Nutrition, Justus Liebig University, 35392 Giessen, Germany. ${ }^{2}$ Center for Biotechnology CeBiTec, Bielefeld University, 33615 Bielefeld, Germany. ${ }^{3}$ Institute of Bioinformatics and Systems Biology, Justus Liebig University, 35392 Giessen, Germany.

Received: 17 December 2020 Accepted: 16 July 2021

Published online: 24 August 2021

\section{References}

1. Marschner P, Yang C-H, Lieberei R, Crowley DE. Soil and plant specific effects on bacterial community composition in the rhizosphere. Soil Biol Biochem. 2001;33(11):1437-45. https://doi.org/10.1016/S0038-0717(01)00052-9.

2. Lagunas B, Schäfer P, Gifford ML. Housing helpful invaders: the evolutionary and molecular architecture underlying plant root-mutualist microbe interactions. J Exp Bot. 2015;66(8):2177-86. https://doi.org/10.1093/jxb/erv038.

3. Kogel KH, Franken P, Hückelhoven R. Endophyte or parasite - what decides? Curr Opin Plant Biol. 2006;9(4):358-63. https://doi.org/10.1016/j.pbi.2006.05.001.

4. Fesel PH, Zuccaro A. Dissecting endophytic lifestyle along the parasitism/ mutualism continuum in Arabidopsis. Curr Opin Microbiol. 2016;32:103-12. https://doi.org/10.1016/j.mib.2016.05.008.

5. Kloppholz S, Kuhn H, Requena N. A secreted fungal effector of Glomus intraradices promotes symbiotic biotrophy. Curr Biol. 2011;21(14):1204-9. https://doi.org/10.1016/j.cub.2011.06.044.

6. Doehlemann $G$, Requena N, Schaefer P, Brunner F, O'Connell R, Parker JE. Reprogramming of plant cells by filamentous plant-colonizing microbes. New Phytol. 2014;204(4):803-14. https://doi.org/10.1111/nph.12938.

7. Vishwakarma K, Kumar N, Shandilya C, Mohapatra S, Bhayana S, Varma A. Revisiting plant-microbe interactions and microbial consortia application for enhancing sustainable agriculture: a review. Front Microbiol. 2020;11:3195.

8. Baulcombe D. RNA silencing in plants. Nature. 2004:431(7006):356-63. https://doi.org/10.1038/nature02874.

9. Fang X, Qi Y. RNAi in plants: an Argonaute-centered view. Plant Cell. 2016; 28(2):272-85. https://doi.org/10.1105/tpc.15.00920.

10. Uhse S, Djamei A. Effectors of plant-colonizing fungi and beyond. PLOS Pathog. 2018;14(6):e1006992. https://doi.org/10.1371/journal.ppat.1006992.

11. Akum FN, Steinbrenner J, Biedenkopf D, Imani J, Kogel KH. The Piriformospora indica effector PIIN 08944 promotes the mutualistic Sebacinalean symbiosis. Front Plant Sci. 2015;6:1-12.
12. Weiberg A, Wang M, Lin F-M, Zhao H, Zhang Z, Kaloshian I, et al. Fungal small RNAs suppress plant immunity by hijacking host RNA interference pathways. Science (80-). 2013;342(6154):118-23.

13. Zhang $T$, Zhao YL, Zhao JH, Wang S, Jin Y, Chen ZQ, et al. Cotton plants export microRNAs to inhibit virulence gene expression in a fungal pathogen. Nat Plants. 2016;2(10):1-6.

14. Kellogg EA. Brachypodium distachyon as a genetic model system. Annu Rev Genet. 2015;49(1):1-20. https://doi.org/10.1146/annurev-genet-112414-055135.

15. Qiang $X$, Weiss $M$, Kogel KH, Schäfer P. Piriformospora indica-a mutualistic basidiomycete with an exceptionally large plant host range. Mol Plant Pathol. 2012;13(5):508-18. https://doi.org/10.1111/j.1364-3703.2011.00764.x.

16. Stein E, Molitor A, Kogel KH, Waller F. Systemic resistance in Arabidopsis conferred by the mycorrhizal fungus Piriformospora indica requires jasmonic acid signaling and the cytoplasmic function of NPR1. Plant Cell Physiol. 2008;49(11):1747-51. https://doi.org/10.1093/pcp/pcn147.

17. Deshmukh SD, Kogel KH. Piriformospora indica protects barley from root rot caused by Fusarium graminearum. J Plant Dis Prot. 2007;114(6):263-8. https://doi.org/10.1007/BF03356227.

18. Trzewik A, Maciorowski $R$, Klocke $E$, Orlikowska T. The influence of Piriformospora indica on the resistance of two rhododendron cultivars to Phytophthora cinnamomi and P. plurivora. Biol Control. 2020;140:104121.

19. Fakhro A, Andrade-Linares DR, von Bargen S, Bandte M, Büttner C, Grosch R, et al. Impact of Piriformospora indica on tomato growth and on interaction with fungal and viral pathogens. Mycorrhiza. 2010;20(3):191-200. https://doi. org/10.1007/s00572-009-0279-5.

20. Baltruschat H, Fodor J, Harrach BD, Niemczyk E, Barna B, Gullner G, et al. Salt tolerance of barley induced by the root endophyte Piriformospora indica is associated with a strong increase in antioxidants. New Phytol. 2008;180(2): 501-10. https://doi.org/10.1111/j.1469-8137.2008.02583.x.

21. Waller F, Achatz B, Baltruschat H, Fodor J, Becker K, Fischer M, et al. The endophytic fungus Piriformospora indica reprograms barley to salt-stress tolerance, disease resistance, and higher yield. Proc Natl Acad Sci U S A. 2005;102(38):13386-91. https://doi.org/10.1073/pnas.0504423102.

22. Zuccaro A, Lahrmann U, Güldener U, Langen G, Pfiffi S, Biedenkopf D, et al. Endophytic life strategies decoded by genome and transcriptome analyses of the mutualistic root symbiont Piriformospora indica. PLoS Pathog. 2011;7(10) Serendipita indica genome assembly. 2011. GCA accession number: GCA 000313545.1 (https://www.ebi.ac.uk/ena/browser/view/GCA_000313545.1).

23. Zuccaro A, Basiewicz M, Zurawska M, Biedenkopf D, Kogel KH. Karyotype analysis, genome organization, and stable genetic transformation of the root colonizing fungus Piriformospora indica. Fungal Genet Biol. 2009;46(8): 543-50. https://doi.org/10.1016/j.fgb.2009.03.009.

24. Schäfer P, Pfiffi S, Voll LM, Zajic D, Chandler PM, Waller F, et al. Manipulation of plant innate immunity and gibberellin as factor of compatibility in the mutualistic association of barley roots with Piriformospora indica. Plant J. 2009;59(3):461-74. https://doi.org/10.1111/j.1365-313X.2009.03887.X.

25. Jacobs S, Zechmann B, Molitor A, Trujillo M, Petutschnig E, Likpa V, et al. Broad-spectrum suppression of innate immunity is required for colonization of Arabidopsis roots by the fungus Piriformospora indica. Plant Physiol. 2011; 156(2):726-40. https://doi.org/10.1104/pp.111.176446.

26. Deshmukh S, Hückelhoven $R$, Schäfer $P$, Imani J, Sharma M, Weiss M, et al. The root endophytic fungus Piriformospora indica requires host cell death for proliferation during mutualistic symbiosis with barley. Proc Natl Acad Sci U S A. 2006;103(49):18450-7. https://doi.org/10.1073/pnas.0605697103.

27. Lahrmann U, Ding Y, Banhara A, Rath M, Hajirezaei MR, Döhlemann S, et al. Host-related metabolic cues affect colonization strategies of a root endophyte. Proc Natl Acad Sci U S A. 2013;110(34):13965-70. https://doi. org/10.1073/pnas.1301653110.

28. Scholthof K-BG, Irigoyen S, Catalan P, Mandadi KK. Brachypodium: a monocot grass model genus for plant biology. Plant Cell. 2018;30(8):167394. https://doi.org/10.1105/tpc.18.00083.

29. Vogel J, Hill T. High-efficiency Agrobacterium-mediated transformation of Brachypodium distachyon inbred line Bd21-3. Plant Cell Rep. 2008;27(3):4718. https://doi.org/10.1007/s00299-007-0472-y.

30. Vogel JP, Garvin DF, Mockler TC, Schmutz J, Rokhsar D, Bevan MW, et al. Genome sequencing and analysis of the model grass Brachypodium distachyon. Nature. 2010;463(7282):763-8.

31. Hsia MM, O'Malley R, Cartwright A, Nieu R, Gordon SP, Kelly S, et al. Sequencing and functional validation of the JGI Brachypodium distachyon TDNA collection. Plant J. 2017;91(3):361-70. https://doi.org/10.1111/tpj.13582. 
32. Fitzgerald TL, Powell JJ, Schneebeli K, Hsia MM, Gardiner DM, Bragg JN, et al. Brachypodium as an emerging model for cereal-pathogen interactions. Ann Bot. 2015;115(5):717-31. https://doi.org/10.1093/aob/mcv010.

33. Zhang J, Xu Y, Huan Q, Chong K. Deep sequencing of Brachypodium small RNAs at the global genome level identifies microRNAs involved in cold stress response. BMC Genomics. 2009;10(1):449. https://doi.org/10.1186/14 71-2164-10-449.

34. Bertolini E, Verelst W, Horner DS, Gianfranceschi L, Piccolo V, Inzé D, et al. Addressing the role of microRNAs in reprogramming leaf growth during drought stress in Brachypodium distachyon. Mol Plant. 2013;6(2):423-43. https://doi.org/10.1093/mp/sss160.

35. Šečić E, Zanini S, Kogel KH. Further elucidation of the Argonaute and Dicer protein families in the model grass species Brachypodium distachyon. Front Plant Sci. 2019;10:1332. https://doi.org/10.3389/fpls.2019.01332.

36. Silvestri A, Fiorilli V, Miozzi L, Accotto GP, Turina M, Lanfranco L. In silico analysis of fungal small RNA accumulation reveals putative plant mRNA targets in the symbiosis between an arbuscular mycorrhizal fungus and its host plant. BMC Genomics. 2019;20(1):1-18.

37. Ren B, Wang X, Duan J, Ma J. Rhizobial tRNA-derived small RNAs are signal molecules regulating plant nodulation. Science (80- ). 2019;365:919-22.

38. Ter-Hovhannisyan V, Lomsadze A, Chernoff YO, Borodovsky M. Gene prediction in novel fungal genomes using an $a b$ initio algorithm with unsupervised training. Genome Res. 2008;18(12):1979-90. https://doi.org/1 0.1101/gr.081612.108.

39. Meyer F, Goesmann A, McHardy AC, Bartels D, Bekel T, Clausen J, et al. GenDB--an open source genome annotation system for prokaryote genomes. Nucleic Acids Res. 2003;31(8):2187-95. https://doi.org/10.1093/na r/gkg312.

40. Rupp O, Becker J, Brinkrolf K, Timmermann C, Borth N, Pühler A, et al. Construction of a public $\mathrm{CHO}$ cell line transcript database using versatile bioinformatics analysis pipelines. PLoS One. 2014;9(1):e85568. https://doi. org/10.1371/journal.pone.0085568.

41. Rafiqi M, Jelonek L, Akum NF, Zhang F, Kogel KH. Effector candidates in the secretome of Piriformospora indica, a ubiquitous plant-associated fungus. Front Plant Sci. 2013;4:228.

42. Billmyre RB, Calo S, Feretzaki M, Wang X, Heitman J. RNAi function, diversity, and loss in the fungal kingdom. Chromosome Res. 2013;21 (6-7):561-72. https://doi.org/10.1007/s10577-013-9388-2.

43. Dang Y, Yang Q, Xue Z, Liu Y. RNA interference in fungi: pathways, functions, and applications. Eukaryot Cell. 2011;10(9):1148 LP-1155.

44. Lau P-W, Guiley KZ, De N, Potter CS, Carragher B, MacRae IJ. The molecular architecture of human Dicer. Nat Struct Mol Biol. 2012;19(4):436-40. https:// doi.org/10.1038/nsmb.2268.

45. Cenik ES, Zamore PD. Argonaute proteins. Curr Biol. 2011;21(12):R446-9. https://doi.org/10.1016/j.cub.2011.05.020.

46. Meyers BC, Axtell MJ. MicroRNAs in plants: key findings from the early years. Plant Cell. 2019;31(6):1206-7. https://doi.org/10.1105/tpc.19.00310.

47. Mi S, Cai T, Hu Y, Chen Y, Hodges E, Ni F, et al. Sorting of small RNAs into Arabidopsis Argonaute complexes is directed by the $5^{\prime}$ terminal nucleotide. Cell. 2008;133(1):116-27. https://doi.org/10.1016/j.cell.2008.02.034.

48. Cai Q, Qiao L, Wang M, He B, Lin F-M, Palmquist J, et al. Plants send small RNAs in extracellular vesicles to fungal pathogen to silence virulence genes. Science (80- ). 2018;360:eaar4142.

49. Lahrmann U, Strehmel N, Langen G, Frerigmann H, Leson L, Ding Y, et al. Mutualistic root endophytism is not associated with the reduction of saprotrophic traits and requires a noncompromised plant innate immunity. New Phytol. 2015;207(3):841-57. https://doi.org/10.1111/nph.13411.

50. Tonukari NJ, Scott-Craig JS, Waltonb JD. The Cochliobolus carbonum SNF1 gene is required for cell wall-degrading enzyme expression and virulence on maize. Plant Cell. 2000;12(2):237-47.

51. Zhou H, Lorenz MC. Carnitine acetyltransferases are required for growth on non-fermentable carbon sources but not for pathogenesis in Candida albicans. Microbiology. 2008;154(2):500-9. https://doi.org/10.1099/mic.0.2 007/014555-0.

52. Hyun MW, Yun YH, Kim JY, Kim SH. Fungal and plant phenylalanine ammonia-lyase. Mycobiology. 2011;39(4):257-65. https://doi.org/10.5941/ MYCO.2011.39.4.257.

53. Zhang M, Shen Z, Meng G, Lu Y, Wang Y. Genome-wide analysis of the Brachypodium distachyon (L.) P. Beauv. Hsp90 gene family reveals molecular evolution and expression profiling under drought and salt stresses. PLoS One. 2017;12(12):e0189187. https://doi.org/10.1371/journal.pone.0189187.
54. Brunetti SC, Arseneault MKM, Gulick PJ. Characterization of the Esi3/RCI2/ PMP3 gene family in the Triticeae. BMC Genomics. 2018;19(1):898. https:// doi.org/10.1186/s12864-018-5311-8.

55. Liang $Y$, Jiang $Y$, Du $M$, Li B, Chen $L$, Chen $M$, et al. ZmASR3 from the maize ASR gene family positively regulates drought tolerance in transgenic Arabidopsis. Int J Mol Sci. 2019;20(9):2278. https://doi.org/10.3390/ijms2 0092278.

56. Hayama R, Sarid-Krebs L, Richter R, Fernández V, Jang S, Coupland G. PSEUDO RESPONSE REGULATORs stabilize CONSTANS protein to promote flowering in response to day length. EMBO J. 2017;36(7):904-18. https://doi. org/10.15252/embj.201693907.

57. Li Y, Xu M. CCT family genes in cereal crops: A current overview. Crop J. 2017;5(6):449-58. https://doi.org/10.1016/j.cj.2017.07.001.

58. Voß U, Wilson MH, Kenobi K, Gould PD, Robertson FC, Peer WA, et al. The circadian clock rephases during lateral root organ initiation in Arabidopsis thaliana. Nat Commun. 2015;6(1):7641. https://doi.org/10.1038/ncomms8641.

59. Wahl V, Brand LH, Guo Y-L, Schmid M. The FANTASTIC FOUR proteins influence shoot meristem size in Arabidopsis thaliana. BMC Plant Biol. 2010; 10(1):285. https://doi.org/10.1186/1471-2229-10-285.

60. Zhan X, Shen Q, Wang X, Hong Y. The Sulfoquinovosyltransferase-like enzyme SQD2.2 is involved in flavonoid glycosylation, regulating sugar metabolism and seed setting in rice. Sci Rep. 2017;7(1):4685.

61. Pedrotti L, Mueller MJ, Waller F. Piriformospora indica root colonization triggers local and systemic root responses and inhibits secondary colonization of distal roots. PLoS One. 2013;8(7):e69352. https://doi.org/10.13 71/journal.pone.0069352.

62. Harrach B, Baltruschat $\mathrm{H}$, Barna B, Fodor J, Kogel KH. The mutualistic fungus Piriformospora indica protects barley roots from a loss of antioxidant capacity caused by the necrotrophic pathogen Fusarium culmorum. Mol Plant Microbe Interact. 2013;26(5):599-605. https://doi.org/10.1094/MPMI09-12-0216-R.

63. Ye W, Shen $\mathrm{C}-\mathrm{H}$, Lin $\mathrm{Y}$, Chen $\mathrm{P}-J, \mathrm{Xu} \mathrm{X}$, Oelmüller R, et al. Growth promotion-related miRNAs in Oncidium orchid roots colonized by the endophytic fungus Piriformospora indica. PLoS One. 2014;9(1):e84920. https://doi.org/10.1371/journal.pone.0084920.

64. Jeong D-H, Schmidt SA, Rymarquis LA, Park S, Ganssmann M, German MA, et al. Parallel analysis of RNA ends enhances global investigation of microRNAs and target RNAs of Brachypodium distachyon. Genome Biol. 2013;14(12):R145. https://doi.org/10.1186/gb-2013-14-12-r145.

65. Šečić E, Kogel KH, Ladera-Carmona MJ. Biotic stress-associated microRNA families in plants. J Plant Physiol. 2021;263:153451. https://doi.org/10.1016/j. jplph.2021.153451.

66. Morea E, Silva E, Silva G, Valente G, Barrera C, Vincentz M, et al. Functional and evolutionary analyses of the miR156 and miR529 families in land plants. BMC Plant Biol. 2016;16:40

67. Hackenberg M, Shi B-J, Gustafson P, Langridge P. Characterization of phosphorus-regulated miR399 and miR827 and their isomirs in barley under phosphorus-sufficient and phosphorus-deficient conditions. BMC Plant Biol. 2013;13(1):214. https://doi.org/10.1186/1471-2229-13-214.

68. Baev V, Milev I, Naydenov M, Apostolova E, Minkov G, Minkov l, et al. Implementation of a de novo genome-wide computational approach for updating Brachypodium miRNAs. Genomics. 2011;97(5):282-93. https://doi. org/10.1016/j.ygeno.2011.02.008.

69. Wang B, Sun $Y$, Song $N$, Zhao M, Liu R, Feng $H$, et al. Puccinia striiformis $f$. sp. tritici microRNA-like RNA 1 (Pst-milR1), an important pathogenicity factor of Pst, impairs wheat resistance to Pst by suppressing the wheat pathogenesis-related 2 gene. New Phytol. 2017;215(1):338-50. https://doi. org/10.1111/nph.14577.

70. Lammers PJ, Jun J, Abubaker J, Arreola R, Gopalan A, Bago B, et al. The glyoxylate cycle in an arbuscular mycorrhizal fungus. Carbon flux and gene expression. Plant Physiol. 2001;127(3):1287-98. https://doi.org/10.1104/pp.01 0375.

71. Hynes MJ, Murray SL, Andrianopoulos A, Davis MA. Role of carnitine acetyltransferases in acetyl coenzyme A metabolism in Aspergillus nidulans. Eukaryot Cell. 2011;10(4):547-55. https://doi.org/10.1128/EC.00295-10.

72. Li J, Yu L, Yang J, Dong L, Tian B, Yu Z, et al. New insights into the evolution of subtilisin-like serine protease genes in Pezizomycotina. BMC Evol Biol. 2010;10(1):68. https://doi.org/10.1186/1471-2148-10-68.

73. Corrales Escobosa AR, Rangel Porras RA, Meza Carmen V, Gonzalez Hernandez GA, Torres Guzman JC, Wrobel K, et al. Fusarium oxysporum Adh1 has dual fermentative and oxidative functions and is involved in 
fungal virulence in tomato plants. Fungal Genet Biol. 2011;48(9):886-95. https://doi.org/10.1016/j.fgb.2011.06.004.

74. Jiang J, Yun Y, Yang Q, Shim W-B, Wang Z, Ma Z. A type 2 C protein phosphatase FgPtc3 is involved in cell wall integrity, lipid metabolism, and virulence in Fusarium graminearum. PLoS One. 2011;6(9):e25311. https://doi. org/10.1371/journal.pone.0025311.

75. Xiang Q, Rasmussen C, Glass NL. The ham-2 locus, encoding a putative transmembrane protein, is required for hyphal fusion in Neurospora crassa. Genetics. 2002;160(1):169-80. https://doi.org/10.1093/genetics/160.1.169.

76. Lannoo N, Van Damme EJM. Lectin domains at the frontiers of plant defense. Front Plant Sci. 2014;5:397.

77. Torii KU. Leucine-rich repeat receptor kinases in plants: structure, function, and signal transduction pathways. Int Rev Cytol. 2004;234:1-46. https://doi. org/10.1016/50074-7696(04)34001-5.

78. Mugford ST, Osbourn A. Evolution of serine carboxypeptidase-like acyltransferases in the monocots. Plant Signal Behav. 2010;5(2):193-5. https://doi.org/10.4161/psb.5.2.11093.

79. Corrêa LGG, Riaño-Pachón DM, Schrago CG, dos Santos RV, Mueller-Roeber $B$, Vincentz M. The role of bZIP transcription factors in green plant evolution: adaptive features emerging from four founder genes. PLoS One. 2008;3(8):e2944. https://doi.org/10.1371/journal.pone.0002944.

80. Hirsch S, Oldroyd GED. GRAS-domain transcription factors that regulate plant development. Plant Signal Behav. 2009:4(8):698-700. https://doi.org/1 0.4161/psb.4.8.9176.

81. Ambawat S, Sharma P, Yadav NR, Yadav RC. MYB transcription factor genes as regulators for plant responses: an overview. Physiol Mol Biol Plants. 2013; 19(3):307-21. https://doi.org/10.1007/s12298-013-0179-1.

82. Zanini S, Šečić E, Busche T, Galli M, Zheng Y, Kalinowski J, et al. Comparative analysis of transcriptome and sRNAs expression patterns in the Brachypodium distachyon- Magnaporthe oryzae pathosystems. Int J Mol Sci. 2021;22(2). https://doi.org/10.3390/ijms22020650.

83. Šečić E, Kogel KH. Requirements for fungal uptake of dsRNA and gene silencing in RNAi-based crop protection strategies. Curr Opin Biotech. 2021; 70:136-42. https://doi.org/10.1016/j.copbio.2021.04.001.

84. Murashige T, Skoog F. A revised medium for rapid growth and bio assays with tobacco tissue cultures. Physiol Plant. 1962;15(3):473-97. https://doi. org/10.1111/j.1399-3054.1962.tb08052.x.

85. Pontecorvo G, Roper JA, Hemmons LM, Macdonald KD, Bufton AW. The genetics of Aspergillus nidulans. Ad Genet. 1953;5:141-238. https://doi.org/1 0.1016/S0065-2660(08)60408-3.

86. Resequencing and genome assembly of Serendipita indica (syn. Piriformospora indica). European Nucleotide Archive. 2021. https://www.ebi.a c.uk/ena/browser/view/PRJEB45884

87. Wibberg D, Stadler M, Lambert C, Bunk B, Spröer C, Rückert C, et al. High quality genome sequences of thirteen Hypoxylaceae (Ascomycota) strengthen the phylogenetic family backbone and enable the discovery of new taxa. Fungal Divers. 2021;106:7-28.

88. Wibberg D, Andersson L, Tzelepis G, Rupp O, Blom J, Jelonek L, et al. Genome analysis of the sugar beet pathogen Rhizoctonia solani AG2-2IIIB revealed high numbers in secreted proteins and cell wall degrading enzymes. BMC Genomics. 2016;17(1):245. https:/doi.org/10.1186/s12864-016-2561-1.

89. Koren S, Walenz BP, Berlin K, Miller JR, Bergman NH, Phillippy AM. Canu: scalable and accurate long-read assembly via adaptive k-mer weighting and repeat separation. Genome Res. 2017;27(5):722-36. https://doi.org/10.1101/ gr.215087.116.

90. Walker BJ, Abeel T, Shea T, Priest M, Abouelliel A, Sakthikumar S, et al. Pilon: an integrated tool for comprehensive microbial variant detection and genome assembly improvement. PLoS One. 2014;9(11):e112963. https://doi. org/10.1371/journal.pone.0112963.

91. Li H. Aligning sequence reads, clone sequences and assembly contigs with BWA-MEM. ArXiv. 2013;1303.3997:1-3.

92. Langmead B, Salzberg SL. Fast gapped-read alignment with Bowtie 2. Nat Methods. 2012;9(4):357-9. https://doi.org/10.1038/nmeth.1923.

93. Galagan JE, Calvo SE, Borkovich KA, Selker EU, Read ND, Jaffe D, et al. The genome sequence of the filamentous fungus Neurospora crassa. Nature. 2003:422(6934):859-68 NC12 genome assembly. 2014. GCA accession number: GCA_000182925.2 (https://www.ebi.ac.uk/ena/browser/view/GCA_ 000182925.2).

94. Petersen TN, Brunak S, von Heijne G, Nielsen H. SignalP 4.0: discriminating signal peptides from transmembrane regions. Nat Methods. 2011;8(10):7856. https://doi.org/10.1038/nmeth.1701.
95. Krogh A, Larsson B, von Heijne G, Sonnhammer ELL. Predicting transmembrane protein topology with a hidden markov model: application to complete genomes. J Mol Biol. 2001;305(3):567-80. https://doi.org/10.1 006/jmbi.2000.4315.

96. Emanuelsson O, Nielsen H, Brunak S, von Heijne G. Predicting subcellular localization of proteins based on their $\mathrm{N}$-terminal amino acid sequence. J Mol Biol. 2000;300(4):1005-16. https://doi.org/10.1006/jmbi.2000.3903.

97. Ray P, Chi M-H, Guo Y, Chen C, Adam C, Kuo A, et al. Genome sequence of the plant growth promoting fungus Serendipita vermifera subsp. bescii: The First Native Strain from North America. Phytobiomes J. 2018;2(2):62-3 Serendipita vermifera ssp. bescii NFPB0129 v1.0. (https://mycocosm.jgi.doe. gov/Sebvebe1/Sebvebe1.home.html).

98. Martin F, Aerts A, Ahrén D, Brun A, Danchin EGJ, Duchaussoy F, et al. The genome of Laccaria bicolor provides insights into mycorrhizal symbiosis. Nature. 2008;452(7183):88-92 Laccaria bicolor v2.0. (https://mycocosm.jgi. doe.gov/Lacbi2/Lacbi2.home.html).

99. Blom J, Kreis J, Spänig S, Juhre T, Bertelli C, Ernst C, et al. EDGAR 2.0: an enhanced software platform for comparative gene content analyses. Nucleic Acids Res. 2016:44(W1):W22-8. https://doi.org/10.1093/nar/gkw255.

100. mRNA-seq of Brachypodium distachyon roots inoculated with Serendipita indica (syn. Piriformospora indica). ArrayExpress database at EMBL-EBI. 2021. https://www.ebi.ac.uk/arrayexpress/experiments/E-MTAB-10649

101. Andrews S, Krueger F, Segonds-Pichon A, Biggins L, Krueger C, Wingett S. FastQC: a quality control tool for high throughput sequence data. Babraham; 2016. http://www.bioinformatics.babraham.ac.uk/projects/fastqc [Accessed 1 Feb 2019]

102. Brachypodium distachyon Bd21-3 v1.1 DOE-JGl, http://phytozome.jgi.doe. gov/

103. Kim D, Paggi JM, Park C, Bennett C, Salzberg SL. Graph-based genome alignment and genotyping with HISAT2 and HISAT-genotype. Nat Biotechnol. 2019;37(8):907-15. https://doi.org/10.1038/s41587-019-0201-4.

104. Kupfer DM, Drabenstot SD, Buchanan KL, Lai H, Zhu H, Dyer DW, et al. Introns and splicing elements of five diverse fungi. Eukaryot Cell. 2004;3(5): 1088-100. https://doi.org/10.1128/EC.3.5.1088-1100.2004.

105. Walters B, Lum G, Sablok G, Min XJ. Genome-wide landscape of alternative splicing events in Brachypodium distachyon. DNA Res. 2013;20(2):163-71. https://doi.org/10.1093/dnares/dss041.

106. Anders S, Pyl PT, Huber W. HTSeq--a Python framework to work with highthroughput sequencing data. Bioinformatics. 2015;31(2):166-9. https://doi. org/10.1093/bioinformatics/btu638.

107. Love Ml, Huber W, Anders S. Moderated estimation of fold change and dispersion for RNA-seq data with DESeq2. Genome Biol. 2014;15(12):550 https://doi.org/10.1186/s13059-014-0550-8.

108. Du Z, Zhou X, Ling Y, Zhang Z, Su Z. agriGO: a GO analysis toolkit for the agricultural community. Nucleic Acids Res. 2010 Jul;38(suppl_2):W64-70. https://doi.org/10.1093/nar/gkq310.

109. Sievert C. Interactive web-based data visualization with $R$, plotly, and shiny: Chapman and Hall/CRC; 2020. Available from: https://plotly-r.com. https:// doi.org/10.1201/9780429447273.

110. Wickham H. ggplot2: Elegant graphics for data analysis. New York: SpringerVerlag; 2016. Available from: http://ggplot2.org

111. R Core Team. R: A language and environment for statistical computing. Vienna; 2017. Available from: https://www.r-project.org/

112. Götz S, García-Gómez JM, Terol J, Williams TD, Nagaraj SH, Nueda MJ, et al. High-throughput functional annotation and data mining with the Blast2GO suite. Nucleic Acids Res. 2008;36(10):3420-35. https://doi.org/10.1093/nar/ gkn176.

113. sRNA-seq of Brachypodium distachyon roots inoculated with Serendipita indica (syn. Piriformospora indica). ArrayExpress database at EMBL-EBI. 2021. https://www.ebi.ac.uk/arrayexpress/experiments/E-MTAB-10650

114. Martin M. Cutadapt removes adapter sequences from high-throughput sequencing reads. EMBnet.journal. 2011;17(1):10-12. Next Gener Seq Data Anal - 1014806/ej171200.

115. Langmead B, Trapnell C, Pop M, Salzberg SL. Ultrafast and memory-efficient alignment of short DNA sequences to the human genome. Genome Biol. 2009;10(3):R25. https://doi.org/10.1186/gb-2009-10-3-r25.

116. The RNAcentral Consortium, Petrov Al, Kay SJE, Kalvari I, Howe KL, Gray KA, et al. RNAcentral: a comprehensive database of non-coding RNA sequences. Nucleic Acids Res. 2017;45(D1):D128-34. https://doi.org/10.1093/nar/gkw1008.

117. Johnson NR, Yeoh JM, Coruh C, Axtell MJ. Improved placement of multimapping small RNAs. G3 (Bethesda). 2016;6(7):2103-11. 
118. Zanini S, Šečić E, Jelonek L, Kogel KH. A bioinformatics pipeline for the analysis and target prediction of RNA effectors in bidirectional communication during plant-microbe interactions. Front Plant Sci. 2018;9. https://doi.org/10.3389/fpls.2018.01212.

119. Dai X, Zhao PX. psRNATarget: a plant small RNA target analysis server. Nucleic Acids Res. 2011;39(suppl_2):W155-9. https://doi.org/10.1093/nar/ gkr319.

120. Chen H, Boutros PC. VennDiagram: a package for the generation of highlycustomizable Venn and Euler diagrams in R. BMC Bioinformatics. 2011;12(1): 35. https://doi.org/10.1186/1471-2105-12-35.

121. Livak KJ, Schmittgen TD. Analysis of relative gene expression data using real-time quantitative $P C R$ and the $2-\Delta \Delta C T$ Method. Methods. 2001;25(4): 402-8. https://doi.org/10.1006/meth.2001.1262.

122. Chen C, Ridzon DA, Broomer AJ, Zhou Z, Lee DH, Nguyen JT, et al. Realtime quantification of microRNAs by stem-loop RT-PCR. Nucleic Acids Res. 2005;33(20):e179. https://doi.org/10.1093/nar/gni178.

123. Kramer MF. Stem-Loop RT-qPCR for miRNAs. Curr Protoc Mol Biol. 2011;95: 15.10.1.

\section{Publisher's Note}

Springer Nature remains neutral with regard to jurisdictional claims in published maps and institutional affiliations.

Ready to submit your research? Choose BMC and benefit from:

- fast, convenient online submission

- thorough peer review by experienced researchers in your field

- rapid publication on acceptance

- support for research data, including large and complex data types

- gold Open Access which fosters wider collaboration and increased citations

- maximum visibility for your research: over $100 \mathrm{M}$ website views per year

At $\mathrm{BMC}$, research is always in progress.

Learn more biomedcentral.com/submissions 